\title{
Electrochemical and Photophysical Properties of Ruthenium(II) Complexes Equipped with Sulfurated Bipyridine Ligands
}

\author{
Shao-An Hua, Mauricio Cattaneo, Manuel Oelschlegel, Moritz Heindl, Lucius Schmid, \\ Sebastian Dechert, Oliver S. Wenger, Inke Siewert,* Leticia González,* and Franc Meyer*
}

Cite This: https://dx.doi.org/10.1021/acs.inorgchem.0c00220

Read Online

ACCESS

山ll Metrics \& More

回 Article Recommendations

(s) Supporting Information

ABSTRACT: The development of new solar-to-fuel scenarios is of great importance, but the construction of molecular systems that convert sunlight into chemical energy represents a challenge. One specific issue is that the molecular systems have to be able to accumulate redox equivalents to mediate the photodriven transformation of relevant small molecules, which mostly involves the orchestrated transfer of multiple electrons and protons. Disulfide/ dithiol interconversions are prominent $2 \mathrm{e}^{-} / 2 \mathrm{H}^{+}$couples and can play an important role for redox control and charge storage. With this background in mind, a new photosensitizer $\left[\mathrm{Ru}\left({ }^{S-S} \mathrm{bpy}\right)\right.$ $\left.(\text { bpy })_{2}\right]^{2+}\left(1^{2+}\right)$ equipped with a disulfide functionalized bpy ligand ( ${ }^{S-S}$ bpy, bpy $=2,2^{\prime}$-bipyridine) was synthesized and has been

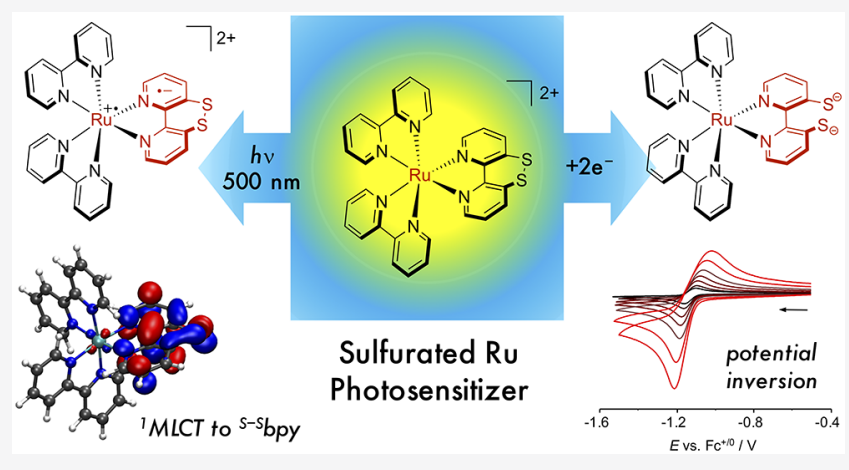
comprehensively studied, including structural characterization by

$\mathrm{X}$-ray diffraction. In-depth electrochemical studies show that the ${ }^{\mathrm{S}-\mathrm{S}}$ bpy ligand in $\mathbf{1}^{2+}$ can be reduced twice at moderate potentials (around $-1.1 \mathrm{~V} \mathrm{vs} \mathrm{Fc}^{+/ 0}$ ), and simulation of the cyclic voltammetry $(\mathrm{CV})$ traces revealed potential inversion $\left(E_{2}>E_{1}\right)$ and allowed to derive kinetic parameters for the sequential electron-transfer processes. However, reduction at room temperature also triggers the ejection of one sulfur atom from $1^{2+}$, leading to the formation of $\left[\mathrm{Ru}\left({ }^{\mathrm{S}} \mathrm{bpy}\right)(\mathrm{bpy})_{2}\right]^{2+}\left(2^{2+}\right)$. This chemical reaction can be suppressed by decreasing the temperature from 298 to $248 \mathrm{~K}$. Compared to the archetypical photosensitizer $\left[\mathrm{Ru}(\mathrm{bpy})_{3}\right]^{2+}, \mathbf{1}^{2+}$ features an additional low energy optical excitation in the MLCT region, originating from charge transfer from the metal center to the ${ }^{S-S}$ bpy ligand (aka MSCT) according to time-dependent density functional theory (TD-DFT) calculations. Analysis of the excited states of $\mathbf{1}^{2+}$ on the basis of ground-state Wigner sampling and using charge-transfer descriptors has shown that bpy modification with a peripheral disulfide moiety leads to an energy splitting between charge-transfer excitations to the ${ }^{S-S}$ bpy and the bpy ligands, offering the possibility of selective charge transfer from the metal to either type of ligands. Compound $\mathbf{1}^{2+}$ is photostable and shows an emission from a ${ }^{3}$ MLCT state in deoxygenated acetonitrile with a lifetime of 109 ns. This work demonstrates a rationally designed system that enables future studies of photoinduced multielectron, multiproton PCET chemistry.

\section{INTRODUCTION}

The transformation of small molecules relevant for sustainable energy scenarios, specifically the generation of solar fuels, is a key challenge of current research addressing urgent energy storage needs. Light-driven fuel production requires the development of catalysts capable of mediating challenging transformations of rather inert molecules, which mostly involve the orchestration of complex multielectron, multiproton transfers to/from the substrate. ${ }^{1}$ Furthermore, light-harvesting systems need to be integrated into this proton/electrontransfer scheme in order to achieve the light-to-chemical energy conversion. ${ }^{2}$

During the past few decades, photoinduced single electron transfer in donor-acceptor compounds has been thoroughly investigated. However, the above light-driven multielectrontransfer processes are still difficult to achieve. Therefore, recent years have seen considerable growth in interest toward photoinduced multielectron transfer and the light-driven charge accumulation. ${ }^{3}$ Despite the major efforts relying on the usage of sacrificial reagents, currently few examples of fully integrated systems capable of photoinduced multielectron transfer have been introduced. ${ }^{4}$ Among them, ruthenium(II) polypyridine-type complexes are often chosen as building blocks for the construction of covalently linked donorphotosensitizer-acceptor systems, because they exhibit favorable excited-state and redox properties. While synthetically the assembly of such metal-containing building blocks with

Received: January 21, 2020 
covalently linked ligands is feasible, the preparation of multimetallic complexes is particularly tedious. For simplicity, an alternative approach is the design of new polypridyl chelating ligands capable of storing multiple charges.

Previously, we reported a bipyridine analogue ligand equipped with a peripheral disulfide moiety $\left({ }^{\mathrm{S}}-\mathrm{S}\right.$ bpy, bpy $=$ $2,2^{\prime}$ bipyridine, Figure 1), which exhibits two chemically

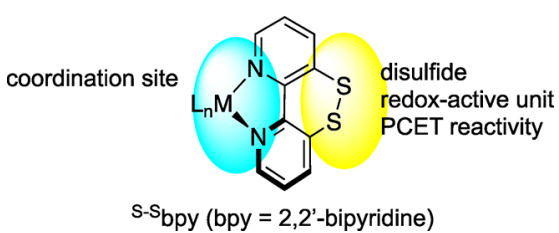

Figure 1. Dual-functionality of the ${ }^{\mathrm{S}-\mathrm{S}}$ bpy ligand.

reversible reduction processes. ${ }^{5}$ In-depth electrochemical studies in combination with density functional theory (DFT) computations were conducted to unravel the sequence of redox events. In the presence of water, the protonation of free

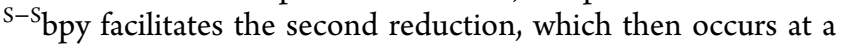
slightly lower potential than the first one; hence, protonation triggers potential inversion and switches the mechanism from $E E C$ to $E C E C$ ( $E=$ electrochemical step, $C=$ chemical step). This is reminiscent of related aromatic disulfide molecules such as dibenzo[1,2]dithiins that are capable of promoting the uptake of multiple electrons through redox potential inversion. ${ }^{4 a, 6}$ The dual functionality of the ${ }^{S-S}$ bpy ligand, i.e., the combination with its $N, N^{\prime}$-chelate site and the backside disulfide/dithiol $2 \mathrm{H}^{+} / 2 \mathrm{e}^{-}$switch, offers interesting prospects when decorating common $4 \mathrm{~d}^{6}$ and $5 \mathrm{~d}^{6}$ transition metal photoabsorbers with this new sulfurated bpy derivative. Inter alia, such molecular design could potentially benefit the storage of redox equivalents and enable photoinduced multielectron/ proton-transfer reactions, which are of essential importance for solar fuel production.

Herein, we present first results in this direction, viz., the preparation and comprehensive characterization of a novel $\mathrm{Ru}^{\mathrm{II}}$ complex equipped with one ${ }^{S-S}$ bpy ligand; a related complex with a modified bpy ligand featuring a single $S$ atom ( ${ }^{S}$ bpy) is also studied. Both complexes have been structurally authenticated and well characterized by electrochemistry, providing detailed understanding of their ground-state nature. The photophysical properties have also been investigated and interpreted with the help of time-dependent density functional theory (TD-DFT) calculations that allow for assignment of the optical transitions.

\section{EXPERIMENTAL SECTION}

General Considerations and Materials. All manipulations of air- and moisture-sensitive materials were carried out under an anaerobic and anhydrous atmosphere of dry argon using standard Schlenk techniques or in a $\mathrm{N}_{2}$-filled MBraun glovebox. [Ru(bpy) $\left.)_{2} \mathrm{Cl}_{2}\right],{ }^{7}$ [Hdmf $](\mathrm{OTf})$ (dmf is dimethylformamide; $\mathrm{OTf}^{-}=$ $\left.\mathrm{CF}_{3} \mathrm{SO}_{3}^{-}\right),{ }^{8}{ }^{-5} \mathrm{bpy}^{5}$ and ${ }^{\mathrm{b}} \mathrm{byy}^{5}$ were prepared according to the reported literature procedures. All used chemicals were reagent grade. $\mathrm{CH}_{3} \mathrm{CN}$ was freshly distilled for electrochemical measurements. Tetrakis ( $n$-butyl)ammonium hexafluorophosphate $\left({ }^{n} \mathrm{Bu}_{4} \mathrm{NPF}_{6}\right)$ was dried and stored in the glovebox.

Instrumentation. IR spectra were measured with $\mathrm{KBr}$ pellets using a Digilab Excalibur Series FTS 3000 or Bruker Vertex 70 spectrometer. UV-vis spectra of solutions in quartz cuvettes were recorded with an Agilent Cary 60 spectrometer. Steady-state absorption and luminescence spectra were recorded using a Cary
5000 spectrophotometer from Varian and a Fluorolog-3-22 instrument from Horiba Jobin-Yvon, respectively. Transient absorption and emission studies were carried out with a LP920-KS apparatus from Edinburgh Instruments. Excitation at 430 and $450 \mathrm{~nm}$ was achieved by a Quantel Brilliant Nd:YAG laser equipped with an OPO from Opotek. Excitation at $532 \mathrm{~nm}$ was achieved by a frequency doubled Nd:YAG laser (Quantel Brilliant, pulse width ca. $10 \mathrm{~ns}$ ). For detection of transient absorption spectra, an iCCD camera from Andor was used, whereas kinetic traces at a single wavelength were recorded using a photomultiplier tube. Cyclic voltammetry (CV) experiments were measured under an argon atmosphere with a Gamry Interface Reference 600 potentiostat equipped with a three electrode setup consisting of a $3 \mathrm{~mm}$ glassy carbon working electrode (WE), a platinum wire counter electrode (CE), and a $\mathrm{Ag}$ wire as pseudoreference electrode (RE). ${ }^{n} \mathrm{Bu}_{4} \mathrm{NPF}_{6}(0.2 \mathrm{M})$ in deoxygenated dry $\mathrm{CH}_{3} \mathrm{CN}$ was used as the supporting electrolyte and was prepared in the glovebox. Ferrocene was used as an internal standard, and the data were referenced to the $\mathrm{Fc}^{+/ 0}$ redox couple at the respective temperature. Corrections for the temperature-dependent potential shift of $\mathrm{Fc}$ are explained in the Supporting Information. $i R$ compensation was applied by the positive feedback method, which is implemented in the Gamry software package. Controlled-potential coulometry (CPC) was performed in a glovebox under a nitrogen atmosphere with a Gamry Interface 1000B, using a Pt mesh (WE), a Pt wire (CE), and a Ag wire (RE) in a glass-fritted compartment cell. Data were analyzed by Gamry Framework software. (Spectro)electrochemistry experiments were performed in a glovebox under a nitrogen atmosphere with an Interface $1000 \mathrm{~B}$ potentiostat, Deuterium/Tungsten light source (BWTEK), Exemplar LS spectrometer (BWTEK), and quartz cuvettes. A platinum mesh was used as the working electrode, a platinum wire was used as the auxiliary electrode, and a $\mathrm{Ag}$ wire was used as the reference electrode. ${ }^{\mathrm{n}} \mathrm{Bu}_{4} \mathrm{NPF}_{6}(0.2 \mathrm{M})$ in $\mathrm{MeCN}$ was used as supporting electrolyte. The potential was controlled by Gamry Framework software, and the data was analyzed by BWSpec software. NMR spectra were recorded on Avance DRX 500 (Bruker), Avance 500 Ultrashield (Bruker), Avance 300 (Bruker), and Avance III 300 (Bruker) instruments in $\mathrm{CDCl}_{3}$ or $\mathrm{CD}_{3} \mathrm{CN}$, with residual protons as internal references. Mass spectrometry was performed with a Finnigan MAT 8200 (EI-MS) or a Bruker HTC Ultra (ESI-MS). Combustion analyses were performed by the Analytic Service at the Department of Chemistry of the University of Göttingen. X-ray diffraction data were collected on a STOE IPDS II with graphite monochromated Mo $\mathrm{K} \alpha$ radiation $(\lambda=$ $0.71073 \AA$ ) by use of $\omega$ scans at $-140{ }^{\circ} \mathrm{C}$. Details of the X-ray crystallographic structure determinations are provided in the Supporting Information. CCDC 1979158 and 1979159 contain the supplementary crystallographic data for this paper. These data can be obtained free of charge from The Cambridge Crystallographic Data Centre via http://www.ccdc.cam.ac.uk/data request/cif.

Synthesis. $\left[R u\left({ }^{S-S}\right.\right.$ bpy $\left.)(b p y)_{2}\right]\left(P F_{6}\right)_{2}\left(1\left(\bar{P} F_{6}\right)_{2}\right) .{ }^{S-S}$ bpy $(218 \mathrm{mg}$, $1.00 \mathrm{mmol}, 1.00$ equiv) and $\left[\mathrm{Ru}(\mathrm{bpy})_{2} \mathrm{Cl}_{2}\right](520 \mathrm{mg}, 1.00 \mathrm{mmol}, 1.00$ equiv) in $\mathrm{MeOH}(20 \mathrm{~mL})$ were placed in a $50 \mathrm{~mL}$ round-bottom Schlenk flask. The mixture was degassed and heated at $60{ }^{\circ} \mathrm{C}$ in the dark overnight. After cooling to room temperature (RT), the dark violet suspension was filtered, and to the resulting deep red solution, $300 \mathrm{mg}$ of $\mathrm{KPF}_{6}$ was added and the mixture was stirred for $30 \mathrm{~min}$. The solvent was removed under reduced pressure, and the solid was extracted with $\mathrm{CH}_{2} \mathrm{Cl}_{2}(100 \mathrm{~mL})$. The crude product was further purified by column chromatography (Alox, with $\mathrm{CH}_{3} \mathrm{CN}$ /ethyl acetate: $1 / 10$ as eluent). The amount of solvent was reduced to around $10 \mathrm{~mL}$, and hexane was added to the solution to precipitate the final product as red powder. This powder was subsequently washed with diethyl ether and dried under a vacuum (437 mg, 47\%). Deep red crystals suitable for X-ray diffraction were obtained by the slow diffusion of diethyl ether into a solution of $\mathbf{1}\left(\mathrm{PF}_{6}\right)_{2}$ in $\mathrm{CH}_{3} \mathrm{CN} /$ acetone. Anal. calc for $\mathrm{C}_{36} \mathrm{H}_{34} \mathrm{~N}_{8} \mathrm{~F}_{12} \mathrm{P}_{2} \mathrm{O}_{2} \mathrm{RuS}_{2}$ : \% C 39.09, \% H 2.41, \% N 9.12, \% S 6.96. Found: \% C 39.32, \% H 2.34, \% N 9.04, \% S 6.94 . IR (KBr pellets): $\nu 3117(\mathrm{w}), 3084(\mathrm{w}), 1602(\mathrm{~m}), 1559(\mathrm{w}), 1467$ $(\mathrm{m}), 1446(\mathrm{~m}), 1420(\mathrm{~m}), 1409(\mathrm{~m}), 1313(\mathrm{w}), 1292(\mathrm{w}), 1271(\mathrm{w})$, $1243(\mathrm{w}), 1215(\mathrm{w}), 1203(\mathrm{w}), 1163(\mathrm{w}), 1124(\mathrm{w}), 1112(\mathrm{w}), 1068$ 
(w), $1036(\mathrm{w}), 875(\mathrm{~m}), 833$ (s), 800 (s), 760 (s), 731 (s), 719 (s), $706(\mathrm{~m}), 660(\mathrm{~m}) \mathrm{cm}^{-1} .{ }^{1} \mathrm{H}$ NMR spectrum $\left(500 \mathrm{MHz}, \mathrm{CD}_{3} \mathrm{CN}\right): \delta$ $8.50\left(7^{\text {bpy }}\right.$, ddd, $2 \mathrm{H}, J_{7 \mathrm{bpy}-8 \mathrm{bpy}}=8.2 \mathrm{~Hz}, J_{7 \mathrm{bpy}-9 \mathrm{bpy}}=1.4 \mathrm{~Hz}, J_{7 \mathrm{bpy}-10 \mathrm{bpy}}=$ $0.8 \mathrm{~Hz}), 8.49\left(4^{\text {bpy }}\right.$, ddd, $2 \mathrm{H}, J_{4 \text { bpy }-3 \text { bpy }}=8.2 \mathrm{~Hz}, J_{4 \text { bpy }-2 \mathrm{bpy}}=1.4 \mathrm{~Hz}$, $\left.J_{4 \text { bpy-1bpy }}=0.8 \mathrm{~Hz}\right), 8.10\left(8^{\text {bpy }}, 2 \times \mathrm{dd}, 2 \mathrm{H}, J_{8 \mathrm{bpy}-7 \mathrm{bpy}}=8.2 \mathrm{~Hz}\right.$, $\left.J_{8 \text { bpy-9bpy }}=1.4 \mathrm{~Hz}\right), 8.05\left(3^{\text {bpy }}, 2 \times \mathrm{dd}, 2 \mathrm{H}, J_{3 \mathrm{bpy}-4 \mathrm{bpy}}=8.2 \mathrm{~Hz}\right.$, $\left.J_{3 \mathrm{bpy}-2 \mathrm{bpy}}=1.4 \mathrm{~Hz}\right), 7.89\left(3, \mathrm{dd}, 2 \mathrm{H} J_{3-2}=8.1 \mathrm{~Hz}, J_{3-1}=1.3 \mathrm{~Hz}\right), 7.83$ $\left(10^{\text {bpy }}\right.$, ddd, $2 \mathrm{H}, J_{10 \mathrm{bpy}-9 \mathrm{bpy}}=5.7 \mathrm{~Hz}, J_{10 \mathrm{bpy}-8 \mathrm{bpy}}=1.5 \mathrm{~Hz}, J_{10 \mathrm{bpy}-7 \mathrm{bpy}}=$ $0.8 \mathrm{~Hz}), 7.65\left(1^{\mathrm{bpy}}\right.$, ddd, $2 \mathrm{H}, J_{1 \mathrm{bpy}-2 \mathrm{bpy}}=5.7 \mathrm{~Hz}, J_{1 \mathrm{bpy}-3 \mathrm{bpy}}=1.5 \mathrm{~Hz}$, $\left.J_{1 \mathrm{bpy}-4 \mathrm{bpy}}=0.8 \mathrm{~Hz}\right), 7.62\left(1, \mathrm{dd}, 2 \mathrm{H}, J_{1-2}=5.6 \mathrm{~Hz}, J_{1-3}=1.3 \mathrm{~Hz}\right)$, $7.47\left(9^{\text {by }}, 2 \times \mathrm{dd}, 2 \mathrm{H}, J_{9 \mathrm{bpy}-10 \mathrm{bpy}}=5.7 \mathrm{~Hz}, J_{9 \mathrm{bpy}-8 \mathrm{bpy}}=1.4 \mathrm{~Hz}\right), 7.39$ $\left(2^{\text {bpy }}, 2 \times \mathrm{dd}, 2 \mathrm{H}, J_{2 \text { bpy }-1 \text { bpy }}=5.7 \mathrm{~Hz}, J_{2 \text { bpy }-3 \text { bpy }}=1.4 \mathrm{~Hz}\right), 7.30(2, \mathrm{dd}$, $\left.2 \mathrm{H}, J_{2-3}=8.1 \mathrm{~Hz}, J_{2-1}=5.6 \mathrm{~Hz}\right) \cdot{ }^{3} \mathrm{C}\left\{{ }^{1} \mathrm{H}\right\} \mathrm{NMR}(500 \mathrm{MHz}$, $\left.\mathrm{CD}_{3} \mathrm{CN}\right): \delta 157.80\left(6^{\text {bpy }}\right), 157.76\left(5^{\text {bpy }}\right), 155.58(4), 152.95\left(10^{\text {bpy }}\right)$, $152.66\left(1^{\text {bpy }}\right), 151.96(1), 139.14\left(8^{\text {bpy }}\right), 139.10\left(3^{\text {bpy }}\right), 137.52(3)$, 135.75 (5), 129.11 (2), 128.72 (9 $\left.9^{\text {bpy }}\right), 128.68\left(2^{\text {bpy }}\right), 125.37$ $\left(7^{\text {bpy }}, 4^{\text {bpy }}\right)$. ESI $(+)$-MS $\left(\mathrm{CH}_{3} \mathrm{CN}, m / z\right):[\mathrm{M}]^{2+} 316.0$ (100\%), $[\mathrm{M}+$ $\left.\mathrm{PF}_{6}\right]^{+} 777.0$ (50\%). UV-vis $\left(\mathrm{CH}_{3} \mathrm{CN}\right): \lambda_{\max }\left(\mathrm{nm}, \varepsilon\left[\mathrm{L} \mathrm{mol}^{-1} \mathrm{~cm}^{-1}\right]\right)$ : 244 (26400), 286 (73900), 318 (19600), 398 (8000), 435 (11300), $492(8500)$.

$\left[R u\left({ }^{S} b p y\right)(b p y)_{2}\right]\left(P F_{6}\right)_{2} \quad\left(2\left(P F_{6}\right)_{2}\right)$. ${ }^{s}$ bpy $(93 \mathrm{mg}, 0.50 \mathrm{mmol}, 1.0$ equiv) and $\left[\mathrm{Ru}(\text { bpy })_{2} \mathrm{Cl}_{2}\right](260 \mathrm{mg}, 0.500 \mathrm{mmol}, 1.00$ equiv $)$ in $\mathrm{MeOH}(15 \mathrm{~mL})$ were placed in a $50 \mathrm{~mL}$ round-bottom Schlenk flask. The mixture was degassed and heated to $70{ }^{\circ} \mathrm{C}$ in the dark overnight. After cooling to RT, the dark violet suspension was filtered, and to the resulting deep orange solution, $300 \mathrm{mg}$ of $\mathrm{KPF}_{6}$ was added and the mixture was stirred for $30 \mathrm{~min}$. The solvent was removed under reduced pressure, and the solid was extracted with $\mathrm{CH}_{2} \mathrm{Cl}_{2}(40 \mathrm{~mL})$. The crude product was purified by column chromatography (Alox, with $\mathrm{CH}_{3} \mathrm{CN} /$ ethyl acetate: $1 / 10$ as eluent) to give the target compound (302 mg, 68\%). Orange-red crystals suitable for X-ray diffraction were obtained by slow diffusion of diethyl ether into a solution of $2\left(\mathrm{PF}_{6}\right)_{2}$ in $\mathrm{CH}_{3} \mathrm{CN}$. Anal. calc for $\mathrm{C}_{30} \mathrm{H}_{22} \mathrm{~N}_{6} \mathrm{~F}_{12} \mathrm{P}_{2} \mathrm{RuS}$. $\mathrm{H}_{2} \mathrm{O}: \%$ C 39.70, \% H 2.66, \% N 9.26, \% S 3.53. Found: \% C 39.56, \% H 2.73, \% N 9.57, \% S 3.10. IR (KBr pellets): $\nu 3115$ (w), $3084(\mathrm{w})$, 1604 (w), $1464(\mathrm{~m}), 1448(\mathrm{~m}), 1425(\mathrm{~m}), 1405$ (m), $1312(\mathrm{w}), 1271$ $(\mathrm{w}), 1243(\mathrm{w}), 1226(\mathrm{w}), 1203(\mathrm{w}), 1161(\mathrm{w}), 1125(\mathrm{w}), 1108(\mathrm{w})$, $1064(\mathrm{w}), 890(\mathrm{~m}), 874(\mathrm{~m}), 831(\mathrm{~s}), 786(\mathrm{~s}), 754(\mathrm{~s}), 728(\mathrm{~s}), 715$ $(\mathrm{s}), 611(\mathrm{~m}) \mathrm{cm}^{-1} .{ }^{1} \mathrm{H}$ NMR spectrum $\left(500 \mathrm{MHz}, \mathrm{CD}_{3} \mathrm{CN}\right): \delta 8.54$ $\left(3, \mathrm{dd}, 2 \mathrm{H}, J_{3-2}=8.4 \mathrm{~Hz}, J_{3-1}=0.8 \mathrm{~Hz}\right), 8.50\left(7^{\text {bpy }}\right.$, ddd, $2 \mathrm{H}, J_{7 \text { bpy }-8 \text { bpy }}$ $\left.=8.1 \mathrm{~Hz}, J_{7 \mathrm{bpy}-9 \mathrm{bpy}}=1.4 \mathrm{~Hz}, J_{7 \mathrm{bpy}-10 \mathrm{bpy}}=0.8 \mathrm{~Hz}\right), 8.49\left(4^{\mathrm{bpy}}\right.$, ddd, $2 \mathrm{H}$, $\left.J_{4 \mathrm{bpy}-3 \mathrm{bpy}}=8.1 \mathrm{~Hz}, J_{4 \mathrm{bpy}-2 \mathrm{bpy}}=1.4 \mathrm{~Hz}, J_{4 \mathrm{bpy}-1 \mathrm{bpy}}=0.8 \mathrm{~Hz}\right), 8.10\left(8^{\mathrm{bpy}}\right.$, $\left.2 \times \mathrm{dd}, 2 \mathrm{H}, J_{8 \mathrm{bpy}-7 \mathrm{bpy}}=8.2 \mathrm{~Hz}, J_{8 \mathrm{bpy}-9 \mathrm{bpy}}=1.4 \mathrm{~Hz}\right), 8.05\left(3^{\mathrm{bpy}}, 2 \times \mathrm{dd}\right.$, $\left.2 \mathrm{H}, J_{3 \mathrm{bpy}-4 \mathrm{bpy}}=8.2 \mathrm{~Hz}, J_{3 \mathrm{bpy}-2 \mathrm{bpy}}=1.4 \mathrm{~Hz}\right), 7.83\left(10^{\mathrm{bpy}}\right.$, ddd, $2 \mathrm{H}$, $\left.J_{10 \mathrm{bpy}-9 \mathrm{bpy}}=5.7 \mathrm{~Hz}, J_{10 \mathrm{bpy}-8 \mathrm{bpy}}=1.5 \mathrm{~Hz}, J_{10 \mathrm{bpy}-7 \mathrm{bpy}}=0.8 \mathrm{~Hz}\right), 7.65$ $\left(1^{\mathrm{bpy}}\right.$, ddd, $2 \mathrm{H}, J_{1 \mathrm{bpy}-2 \mathrm{bpy}}=5.7 \mathrm{~Hz}, J_{1 \mathrm{bpy}-3 \mathrm{bpy}}=1.5 \mathrm{~Hz}, J_{1 \mathrm{bpy}-4 \mathrm{bpy}}=0.8$ $\mathrm{Hz}), 7.72\left(1, \mathrm{dd}, 2 \mathrm{H} J_{1-2}=5.3 \mathrm{~Hz}, J_{1-3}=0.9 \mathrm{~Hz}\right), 7.57(2, \mathrm{dd}, 2 \mathrm{H}$ $\left.J_{2-3}=8.4 \mathrm{~Hz}, J_{2-1}=5.3 \mathrm{~Hz}\right), 7.47\left(9^{\mathrm{bpy}}, 2 \times \mathrm{dd}, 2 \mathrm{H}, J_{9 \mathrm{bpy}-10 \mathrm{bpy}}=5.7\right.$ $\left.\mathrm{Hz}, J_{9 \text { bpy-8bpy }}=1.4 \mathrm{~Hz}\right), 7.39\left(2^{\text {bpy }}, 2 \times \mathrm{dd}, 2 \mathrm{H}, J_{2 \text { bpy }-1 \text { bpy }}=5.7 \mathrm{~Hz}\right.$, $\left.J_{2 \text { bpy-3bpy }}=1.4 \mathrm{~Hz}\right) .{ }^{13} \mathrm{C}\left\{{ }^{1} \mathrm{H}\right\} \mathrm{NMR}\left(500 \mathrm{MHz}, \mathrm{CD}_{3} \mathrm{CN}\right): \delta 158.95$ $\left(5^{\text {bpy }}\right), 158.19\left(5^{\text {bpy }}\right), 154.34(5), 153.72\left(10^{\text {bpy }}\right), 153.65\left(1^{\text {bpy }}\right)$, 150.25 (1), 138.82 ( $\left.3^{\text {bpy }}\right), 138.80\left(8^{\text {bpy }}\right), 135.16(4), 134.14(3)$, 128.63 ( $\left.9^{\text {bpy }}\right), 128.23$ ( $\left.2^{\text {by }}\right), 126.60(2), 125.07$ ( $\left.4^{\text {bpy }}\right), 125.03$ ( $\left.7^{\text {bpy }}\right)$. ESI(+)-MS (MeOH, m/z): [M] $]^{2+} 300.0(100 \%),\left[\mathrm{M}+\mathrm{PF}_{6}\right]^{+} 745.1$ (1\%). UV-vis $\left(\mathrm{CH}_{3} \mathrm{CN}\right): \lambda_{\max }\left(\mathrm{nm}, \varepsilon\left[\mathrm{L} \mathrm{mol}^{-1} \mathrm{~cm}^{-1}\right]\right): 234$ (43400), 256 (30600), 286 (71000), 424 (12300), 448 (14800).

Density Functional Theory (DFT) Calculations. $\left[\mathrm{Ru}\left({ }^{\mathrm{S}-\mathrm{S}} \mathrm{bpy}\right)\right.$ $\left.(\text { bpy })_{2}\right]^{2+}\left(1^{2+}\right)$ and $\left[\mathrm{Ru}\left({ }^{S} \text { bpy }\right)(\text { bpy })_{2}\right]^{2+}\left(2^{2+}\right)$ were optimized in $\mathrm{CH}_{3} \mathrm{CN}$ using the B3LYP ${ }^{9}$ hybrid functional combined with the 6$311 \mathrm{G}(\mathrm{d})$ basis set for nonmetal atoms and the LANL2DZ ${ }^{10}$ effective core potential for the ruthenium center (B3LPY/6-311G(d)LANL2DZ). Long-range interactions are taken into account with the Grimme ${ }^{11} \mathrm{D} 3$ dispersion correction. Scalar relativistic effects are included through the use of the second-order Douglas-Kroll-Hess ${ }^{12}$ integrals. Solvent effects were accounted implicitly with the integral equation formalism polarized continuum model ${ }^{13}(\varepsilon=35.688)$. The electronic excited-state calculations were done employing linear response time-dependent DFT (TD-DFT) ${ }^{14}$ at the B3LYP/6$311 \mathrm{G}(\mathrm{d})$-LANL2DZ level of theory on the lowest-lying 20 electronic singlet states. The character of the most important (brightest) electronic excited states at the equilibrium geometry is illustrated using leading natural transition orbital ${ }^{15}$ (NTO) pairs. All calculations have been carried out using the Gaussian $09^{16}$ suite of programs.

The calculation of the absorption spectra is done by convoluting pairs of excitation energies and oscillator strengths of a set of 200 geometries obtained from a ground-state Wigner sampling ${ }^{17}$ to take into account nuclear motion. Gaussian functions with a fwhm of 0.15 $\mathrm{eV}$ were used in the convolution. The $4000(20 \times 200)$ resulting excited states were analyzed using charge-transfer descriptors ${ }^{18}$ as implemented in the TheoDORE ${ }^{19}$ program package. For this analysis, the complexes were divided into four fragments: the ${ }^{\mathrm{S}-\mathrm{S}}$ bpy or ${ }^{\mathrm{S}}$ bpy ligand, respectively (referred to as $S$ ), the Ru metal center (M), and each of the two bpy ligands (L). Accordingly, the excited states are classified according to the most important charge-transfer contribution from the "hole" (the fragment from which the electron is excited) to the "electron" (the fragment to which the electron is excited). If the hole and electron fragment is the same, it is a local excitation, denoted by $\mathrm{MC}$ or LC/SC if this fragment is the $\mathrm{M}$ or the $\mathrm{L} / \mathrm{S}$ ligand. If the hole and electron fragments differ, it is a charge-transfer excitation and will be written as, e.g., MLCT/MSCT when the hole fragment is M and the electron fragment is one of the $\mathrm{L}$ or $\mathrm{S}$ ligands, etc. Within the considered four fragment scheme, there are ten different types of excitations (MC, LC, MLCT, LMCT, LLCT, SC, MSCT, SMCT, LSCT, and SLCT).

\section{RESULTS AND DISCUSSION}

Synthesis and Characterization of Ru" Complexes. The ligand $[1,2]$ dithiino $\left[4,3-b: 5,6-b^{\prime}\right]$ bipyridine ( ${ }^{S-S}$ bpy) was prepared via the previously reported multistep protocol, starting from 2-bromo-3-pyridinol. ${ }^{5}$ The monosulfurated bipyridine, viz., the thiophene derivative ${ }^{\mathrm{s}} \mathrm{bpy},{ }^{20}$ is formed in substantial amounts as a side-product during the synthesis of ${ }^{S}-$ bpy. $^{5}$ Both bpy derivatives can be readily coordinated to $\mathrm{Ru}^{\mathrm{II}}$ (Scheme 1). The mononuclear complex $\left[\mathrm{Ru}\left({ }^{\mathrm{S}-{ }^{-}} \mathrm{bpy}\right)\right.$ (bpy $\left.)_{2}\right]\left(\mathrm{PF}_{6}\right)_{2}\left(\mathbf{1}\left(\mathrm{PF}_{6}\right)_{2}\right)$ was synthesized by heating a solution of $\left[\mathrm{Ru}(\mathrm{bpy})_{2} \mathrm{Cl}_{2}\right]$ and ${ }^{\mathrm{S}-\mathrm{S}}$ bpy in $\mathrm{MeOH}$ to reflux overnight. Anion exchange gave the $\mathrm{PF}_{6}{ }^{-}$salt, which shows high solubility in polar organic solvents. After column chromatography, pure $\left[\mathrm{Ru}\left({ }^{\mathrm{S}-\mathrm{S}} \mathrm{bpy}\right)(\mathrm{bpy})_{2}\right]\left(\mathrm{PF}_{6}\right)_{2}\left(\mathbf{1}\left(\mathrm{PF}_{6}\right)_{2}\right)$ was obtained in $47 \%$ yield. Using ${ }^{S}$ bpy and applying the same synthetic procedure gave $\left[\mathrm{Ru}\left({ }^{\mathrm{S}} \mathrm{bpy}\right)(\mathrm{bpy})_{2}\right]\left(\mathrm{PF}_{6}\right)_{2}\left(2\left(\mathrm{PF}_{6}\right)_{2}\right)$ in $68 \%$ yield.

Scheme 1. Synthetic Routes for Mounting the ${ }^{S-S}$ bpy and ${ }^{s}$ bpy Ligands on the $\left\{R u(b p y)_{2}{ }^{2+}\right\}$ Fragment
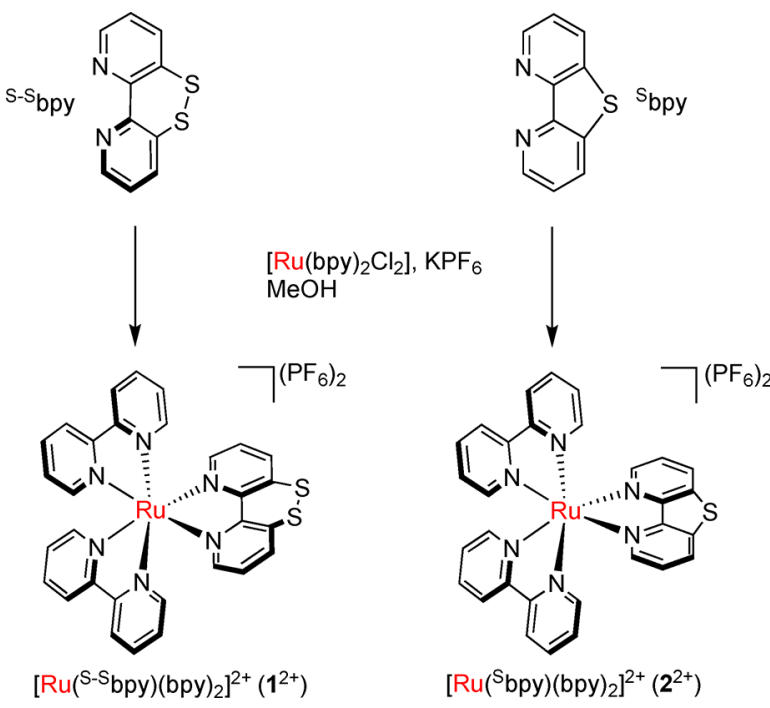

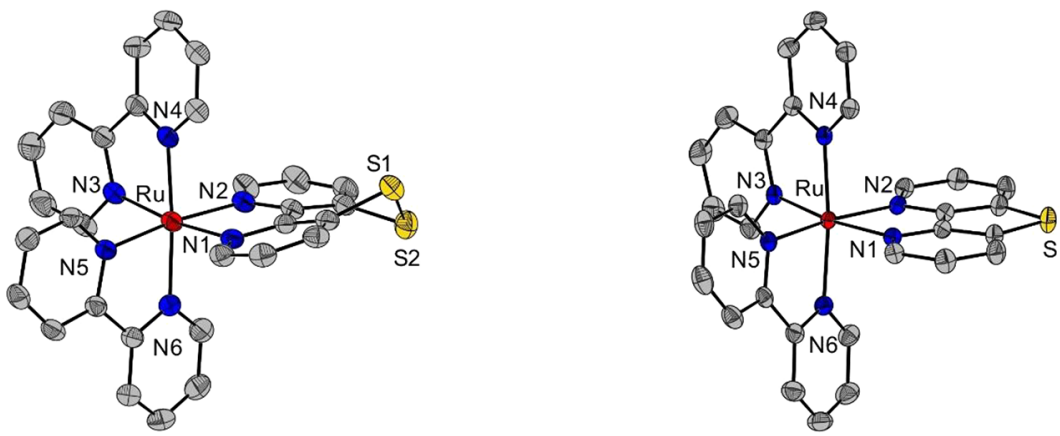

Figure 2. Molecular structures of the cations of $\mathbf{1}^{2+}$ (left) and $\mathbf{2}^{2+}$ (right) shown as $50 \%$ probability thermal ellipsoids. Hydrogens, solvent molecules, and $\mathrm{PF}_{6}{ }^{-}$counterions are omitted for clarity.

Table 1. Selected Bond Lengths and Angles for $1^{2+}$ and $2^{2+a}$

\begin{tabular}{|c|c|c|c|c|c|}
\hline \multirow[b]{2}{*}{ ligand } & \multicolumn{2}{|c|}{$\left[\mathrm{Ru}\left({ }^{\mathrm{S}-\mathrm{s}}\right.\right.$ bpy $\left.)(\mathrm{bpy})_{2}\right]\left(\mathrm{PF}_{6}\right)_{2}\left(\mathbf{1}^{2+}\right)$} & \multirow[b]{2}{*}{ ligand } & \multicolumn{2}{|c|}{$\left[\mathrm{Ru}\left({ }^{\mathrm{S}} \mathrm{bpy}\right)(\mathrm{bpy})_{2}\right]\left(\mathrm{PF}_{6}\right)_{2}\left(\mathbf{2}^{2+}\right)$} \\
\hline & bond & distance $(\AA)$ & & bond & distance $(\AA)$ \\
\hline \multirow[t]{3}{*}{${ }^{s-s}$ bpy } & $\mathrm{Ru}-\mathrm{N}(1)$ & $2.057(2) / 2.097$ & ${ }^{s}$ bpy & $\mathrm{Ru}-\mathrm{N}(1)$ & $2.109(2) / 2.154$ \\
\hline & $\mathrm{Ru}-\mathrm{N}(2)$ & $2.058(2) / 2.097$ & & $\mathrm{Ru}-\mathrm{N}(2)$ & $2.115(2) / 2.152$ \\
\hline & $S(1)-S(2)$ & $2.048(1) / 2.106$ & & & \\
\hline \multirow[t]{2}{*}{ bpy-1 } & $\mathrm{Ru}-\mathrm{N}(3)$ & $2.061(2) / 2.097$ & bpy-1 & $\mathrm{Ru}-\mathrm{N}(3)$ & $2.049(2) / 2.097$ \\
\hline & $\mathrm{Ru}-\mathrm{N}(4)$ & $2.074(2) / 2.103$ & & $\mathrm{Ru}-\mathrm{N}(4)$ & $2.068(2) / 2.083$ \\
\hline \multirow[t]{3}{*}{ bpy-2 } & $\mathrm{Ru}-\mathrm{N}(5)$ & $2.045(2) / 2.096$ & bpy-2 & $\mathrm{Ru}-\mathrm{N}(5)$ & $2.045(2) / 2.083$ \\
\hline & $\mathrm{Ru}-\mathrm{N}(6)$ & $2.066(2) / 2.101$ & & $\mathrm{Ru}-\mathrm{N}(6)$ & $2.054(2) / 2.096$ \\
\hline & atoms & angle (deg) & & atoms & angle (deg) \\
\hline${ }^{s-s}$ bpy & $\mathrm{N}(1)-\mathrm{Ru}-\mathrm{N}(2)$ & $78.79(9) / 78.14$ & ${ }^{s}$ bpy & $\mathrm{N}(1)-\mathrm{Ru}-\mathrm{N}(2)$ & $81.87(7) / 81.07$ \\
\hline bpy-1 & $\mathrm{N}(3)-\mathrm{Ru}-\mathrm{N}(4)$ & $78.68(9) / 78.07$ & bpy-1 & $\mathrm{N}(3)-\mathrm{Ru}-\mathrm{N}(4)$ & $78.80(7) / 78.37$ \\
\hline \multirow[t]{2}{*}{ bpy-2 } & $\mathrm{N}(5)-\mathrm{Ru}-\mathrm{N}(6)$ & $78.73(9) / 78.11$ & bpy-2 & $\mathrm{N}(5)-\mathrm{Ru}-\mathrm{N}(6)$ & $78.72(7) / 78.36$ \\
\hline & planes & dihedral angle (deg) & & planes & dihedral angle (deg) \\
\hline \multirow[t]{2}{*}{${ }^{s-s}$ bpy } & $\mathrm{N}(1)-\mathrm{C}-\mathrm{C}-\mathrm{N}(2)$ & $12.28 / 11.42$ & sbpy & $\mathrm{N}(1)-\mathrm{C}-\mathrm{C}-\mathrm{N}(2)$ & $0.37 / 0.71$ \\
\hline & $C-S(1)-S(2)-C$ & $56.71 / 54.11$ & & & \\
\hline
\end{tabular}

$\mathrm{ESI}(+)$-MS spectra of $\mathrm{CH}_{3} \mathrm{CN}$ solutions of the complexes show major peaks for ions $\left[\mathrm{Ru}\left({ }^{\mathrm{S}-\mathrm{S}} \mathrm{bpy}\right)(\mathrm{bpy})_{2}\right]^{2+}$ and $\left[\mathrm{Ru}\left({ }^{\mathrm{S}-\mathrm{S}} \mathrm{bpy}\right)(\mathrm{bpy})_{2}\left(\mathrm{PF}_{6}\right)\right]^{+}$in case of $\mathbf{1}\left(\mathrm{PF}_{6}\right)_{2}$, or for $[\mathrm{Ru}-$ $\left({ }^{S}\right.$ bpy $\left.)(\text { bpy })_{2}\right]^{2+}$ and $\left[\mathrm{Ru}\left({ }^{\mathrm{S}} \text { bpy }\right)(\mathrm{bpy})_{2}\left(\mathrm{PF}_{6}\right)\right]^{+}$in case of $2\left(\mathrm{PF}_{6}\right)_{2}$, respectively, with the expected isotopic distribution patterns (Figures $\mathrm{S} 1$ and $\mathrm{S} 2$ ). ${ }^{1} \mathrm{H}$ and ${ }^{13} \mathrm{C}$ NMR spectra of both complexes reflect $C_{2}$ symmetry in solution with eight proton signals for the bpy ligands and three proton signals for the ${ }^{\mathrm{S}-\mathrm{S}}$ bpy and $\mathrm{S}$ bpy ligand moieties, respectively. NMR spectra and full spectral assignments are provided in Figures S3-S10.

Single crystals of $\mathbf{1}\left(\mathrm{PF}_{6}\right)_{2}$ and $\mathbf{2}\left(\mathrm{PF}_{6}\right)_{2}$ were obtained by slow diffusion of diethyl ether into $\mathrm{CH}_{3} \mathrm{CN}$ /acetone or $\mathrm{CH}_{3} \mathrm{CN}$ solutions of the complexes, respectively. Molecular structures of the cations are depicted in Figure 2, and selected atom distances and bond angles are listed in Table 1. Both complexes exhibit a distorted octahedral geometry, which is a typical feature for $\mathrm{Ru}^{\mathrm{II}}$ complexes ligated by three ligands that form 5-membered chelate rings. In $\mathbf{1}^{2+}$, bidentate $N, N^{\prime}$ coordination of ${ }^{\mathrm{S}-\mathrm{S}}$ bpy results in $\mathrm{N} 1-\mathrm{C}-\mathrm{C}-\mathrm{N} 2$ and $\mathrm{C}-\mathrm{S} 1-$ $\mathrm{S} 2-\mathrm{C}$ torsion angles of $12.28^{\circ}$ and $56.71^{\circ}$, respectively, as well as a $S-S$ bond length of $2.048 \AA$. For $2^{2+}$ with a single $S$ atom bridge, the two pyridine rings of the ${ }^{S}$ bpy moiety are essentially coplanar, as evidenced by a very small $\mathrm{N} 1-\mathrm{C}-\mathrm{C}-\mathrm{N} 2$ angle of $0.37^{\circ}$. Furthermore, the overall ligand planarity induced by the planar thiophene fragment slightly opens the $N, N^{\prime}$ bite angle, which is reflected by a N1-Ru-N2 angle of $81.87^{\circ}$ in $2^{2+}$, in comparison with the $\mathrm{N} 1-\mathrm{Ru}-\mathrm{N} 2$ angle of $78.9^{\circ}$ in ${ }^{\mathrm{S}-\mathrm{S}} \mathrm{bpy}$ ligated $\mathbf{1}^{2+} . \mathrm{Ru}-\mathrm{N}$ distances are in the typical range, ${ }^{21}$ namely, 2.055-2.070 $\AA$ for $1^{2+}$ and 2.045-2.074 $\AA$ for $2^{2+}$.

UV-vis Absorption, Luminescence, and Transient Absorption Spectroscopy. The UV-vis absorption spectrum of $2^{2+}$ in $\mathrm{CH}_{3} \mathrm{CN}$ solution displays the characteristic bands reminiscent of those of $\left[\mathrm{Ru}(\mathrm{bpy})_{3}\right]^{2+22}$ comprising an intense ligand $\pi-\pi^{*}$ absorption at $287 \mathrm{~nm}$ alongside with broad and less intense MLCT bands at 424 and $448 \mathrm{~nm}$, (Figure $3 \mathrm{a}$ and Table 2). In contrast, the MLCT absorption signature of $\mathbf{1}^{2+}$ is distinctly different and shows three maxima instead of two, with all these absorptions having smaller extinction coefficients. The first two maxima located at 398 and $435 \mathrm{~nm}$ are slightly hypsochromically shifted by approximately $20 \mathrm{~nm}$ compared to $2^{2+}$, but a distinct lowenergy band is observed at around $500 \mathrm{~nm}$. These findings are suggestive of a separated, low-lying MLCT state due to the introduction of the ${ }^{S-S}$ bpy ligand. The assignment of these charge-transfer absorptions will be discussed in detail in the computational part (vide infra).

Solutions of $1^{2+}$ or $2^{2+}$ in deaerated $\mathrm{CH}_{3} \mathrm{CN}$ are emissive when excited at 430 or $400 \mathrm{~nm}$, respectively, as shown in Figure $3 \mathrm{a}$. For $\mathbf{1}^{2+}$, varying the excitation wavelength from 400 to $532 \mathrm{~nm}$ results in the same broad, featureless emission band with maximum intensity at $730 \mathrm{~nm}$ (Figure S12), indicative of a typical Kasha behavior. Time-resolved luminescence decay curves recorded at $730 \mathrm{~nm}$ in deaerated $\mathrm{CH}_{3} \mathrm{CN}$ after excitation of $\mathbf{1}^{2+}$ at 430 and $532 \mathrm{~nm}$ result in identical traces, with a lifetime of 109 ns (Figure 3b,c). A measurement in 

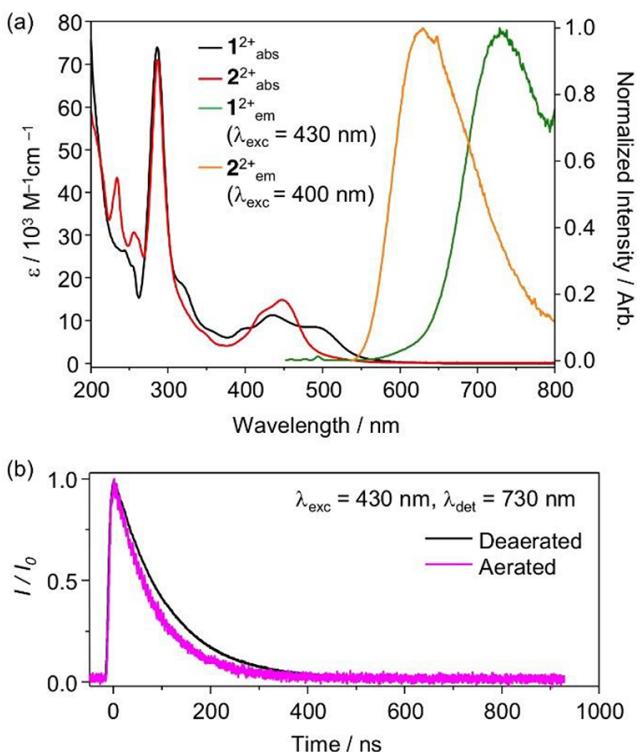

(c)

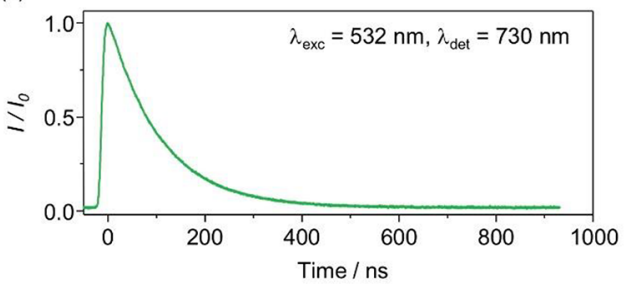

Figure 3. (a) Room temperature absorption and emission spectra of $10^{-5} \mathrm{M}$ solutions of $\mathbf{1}^{2+}$ and $2^{2+}$ in $\mathrm{CH}_{3} \mathrm{CN}$. (b) Luminescence decay curves of the solution of $\mathbf{1}^{2+}$ recorded at $730 \mathrm{~nm}$ after excitation at $430 \mathrm{~nm}$ with laser pulses of $\sim 10 \mathrm{~ns}$ duration. Measurements were performed in both deaerated and aerated $\mathrm{CH}_{3} \mathrm{CN}$. (c) Luminescence decay curve of the solution of $\mathbf{1}^{2+}$ recorded at $730 \mathrm{~nm}$ after excitation at $532 \mathrm{~nm}$.

Table 2. Spectroscopic Properties of the Complexes in $\mathrm{CH}_{3} \mathrm{CN}$ at $293 \mathrm{~K}$

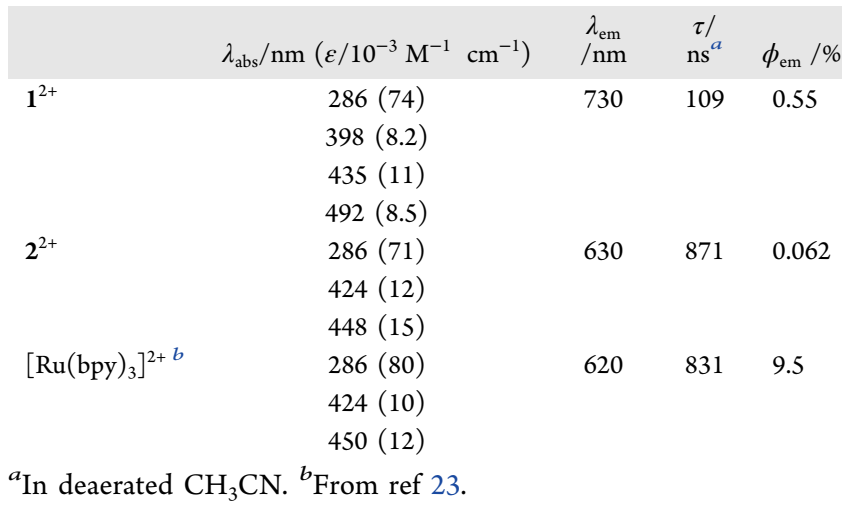

aerated $\mathrm{CH}_{3} \mathrm{CN}$ shows a shorter lifetime of $\tau=84$ ns due to quenching by $\mathrm{O}_{2}$, suggesting that the emission originates from a ${ }^{3} \mathrm{MLCT}$ state. The luminescence quantum yields are $\phi=$ $0.55 \%$ and $0.36 \%$ for excitation at 430 and $500 \mathrm{~nm}$, respectively; both values are lower than for $\left[\mathrm{Ru}(\mathrm{bpy})_{3}\right]^{2+}$ by an order of magnitude (Table 2). This finding might be associated with the remarkable red shift of the emission band. UV-vis spectra of the solutions of $\mathbf{1}^{2+}$ recorded after the kinetic measurements are identical to the original ones, indicating that $\mathbf{1}^{2+}$ is photostable (Figure S13). In contrast,
$2^{2+}$ shows only a very weak emission with a maximum around $630 \mathrm{~nm}$ (Figure 3a). A biexponential decay was observed for its luminescence (Figure S14), indicating that the luminescence may originate from two different excited states or from two different compounds or conformers. The first component is instrumentally limited $(<10 \mathrm{~ns})$, while the second component is associated with a lifetime of ca. 800 ns. To test the photostability of $2^{2+}$, irradiation experiments were conducted and both UV-vis spectra and luminescence decay curves were recorded at different times after illumination of a $\mathrm{CH}_{3} \mathrm{CN}$ solution of $2^{2+}$ with a $455 \mathrm{~nm}$ LED (Figure S15). In the UVvis spectra, a clear change with increasing irradiation time is obvious. Interestingly, after $10 \mathrm{~min}$ irradiation, the resulting MLCT bands look very similar to those of known [Ru(bpy $\left.)_{2}\left(\mathrm{CH}_{3} \mathrm{CN}\right)_{2}\right]^{2+} ;^{24}$ an overlay of the $\mathrm{UV}-$ vis spectra (Figure S16) confirms that $\left[\mathrm{Ru}(\text { bpy })_{2}\left(\mathrm{CH}_{3} \mathrm{CN}\right)_{2}\right]^{2+}$ and free s bpy (identified by an intense absorption at $230 \mathrm{~nm}$ ) are formed. These findings strongly suggest ${ }^{s}$ bpy ligand dissociation from the metal center after excitation of $2^{2+}$. To further corroborate the photoinduced ligand dissociation, two solutions containing $2^{2+}$ in $\mathrm{CD}_{3} \mathrm{CN}$ were treated with heat or light, respectively, and ${ }^{1} \mathrm{H}$ NMR spectra were recorded (Figure S17). No change was found after heating of $2^{2+}$ at $70{ }^{\circ} \mathrm{C}$ overnight, indicating that $2^{2+}$ is thermostable. In contrast, irradiation with a $440 \mathrm{~nm}$ LED over a period of $1 \mathrm{~h}$ leads to the appearance of ${ }^{1} \mathrm{H}$ NMR signals of $[\mathrm{Ru}-$ (bpy $\left.)_{2}\left(\mathrm{CH}_{3} \mathrm{CN}\right)_{2}\right]^{2+}$ and free ${ }^{\mathrm{S}} \mathrm{bpy}$. We attribute this to the bite angle enlargement of the $\left\{N, N^{\prime}\right\}$-bidentate metal coordination site and, hence, to the reduced ligand field strength of ${ }^{S}$ bpy in which the two pyridines are linked via a single $S$ atom. This facilitates the thermally activated ${ }^{3} \mathrm{MLCT}-{ }^{3} \mathrm{LF}$ ( $\mathrm{LF}=$ ligand field state) conversion and prompts the photoreaction (photosolvation). ${ }^{25}$ In the luminescence decay curves, the long-lived (ca. $800 \mathrm{~ns}$ ) component, which is attributed to the luminescence of $2^{2+}$, disappears over time (Figure S15b and Table S1). Consequently, the instrumentally limited signal is attributed to the degradation product $\left[\mathrm{Ru}(\mathrm{bpy})_{2}\left(\mathrm{CH}_{3} \mathrm{CN}\right)_{2}\right]^{2+}$. The quantum yield of $2^{2+}$ is extremely low $(0.062 \%)$.

To explore the decay characteristics of the emissive excited states of $\mathbf{1}^{2+}$ and to confirm their MLCT nature, transient UVvis absorption spectroscopy was carried out. Figure 4 shows the transient absorption spectra averaged over a period of 200 ns immediately after excitation at 430 and $532 \mathrm{~nm}$, respectively, with laser pulses of ca. $10 \mathrm{~ns}$ duration. A ground-state bleach is observed at 400 to $500 \mathrm{~nm}$, in accordance with the lowest-energy ${ }^{1} \mathrm{MLCT}$ absorption bands in Figure 3a. In addition, excited-state absorption bands at 310 and $370 \mathrm{~nm}$ are observed, similar to the absorption bands observed for ${ }^{3} \mathrm{MLCT}$-excited $\left[\mathrm{Ru}(\mathrm{bpy})_{3}\right]^{2+}$. These signals arise from the $\pi-\pi^{*}$ transitions on the transiently reduced bpy ligand. ${ }^{26}$ Switching the excitation wavelength from 532 to 430 $\mathrm{nm}$ gives an identical transient absorption spectrum. The MLCT bleach at $500 \mathrm{~nm}$ and the transient absorption signal at $370 \mathrm{~nm}$ both exhibit the same decay as the MLCT luminescence at $730 \mathrm{~nm}$, confirming that signals from the same excited states are monitored by emission and transient absorption spectroscopy. The MLCT lifetime $(\tau)$ extractable from the transient absorption data is analogous to that obtained from emission data, and the absorption is also quenched by $\mathrm{O}_{2}$, as shown in the bottom of Figure 4, in line with the findings in Figure $3 \mathrm{~b}$ for emission. In the case of $2^{2+}$, because of its photoinstability only low quality transient 

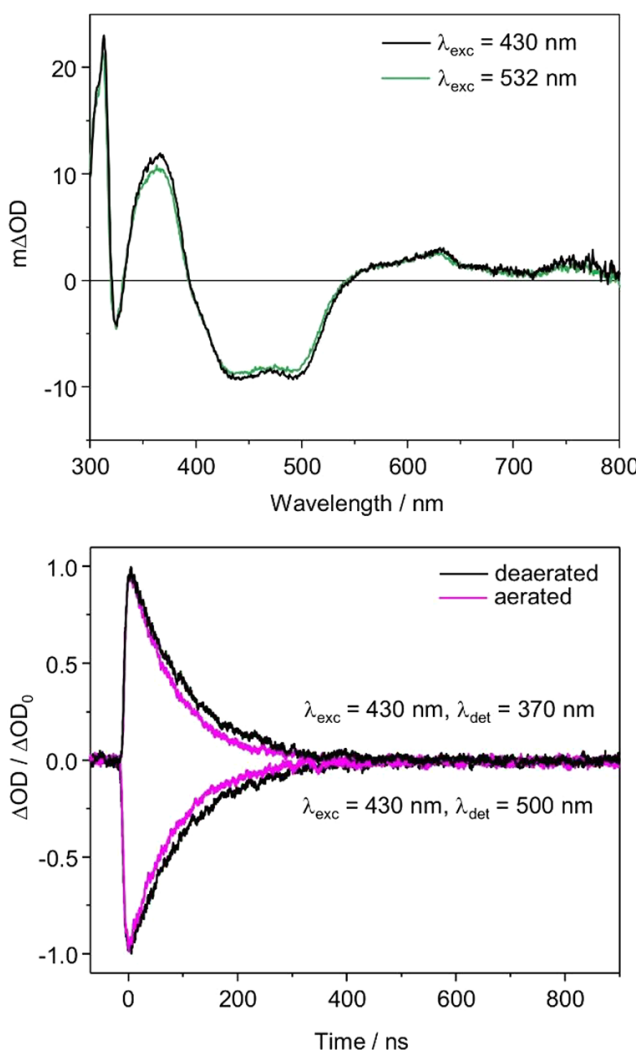

Figure 4. Top: transient absorption spectra measured after excitation of $10^{-5} \mathrm{M}$ solutions of $\mathbf{1}^{2+}$ in deaerated $\mathrm{CH}_{3} \mathrm{CN}$ at 430 (black) and $532 \mathrm{~nm}$ (green) with laser pulses of $\sim 10 \mathrm{~ns}$ duration. The signals were time integrated over $200 \mathrm{~ns}$ immediately after excitation. Bottom: transient absorption decays recorded from deaerated and aerated $\mathrm{CH}_{3} \mathrm{CN}$ solutions of $\mathbf{1}^{2+}$ at $370 \mathrm{~nm}$ and recoveries of the MLCT bleaches at $500 \mathrm{~nm}$.

absorption spectra could be obtained (Figure S18); nevertheless, the bleach at $450 \mathrm{~nm}$ and a new signal at $390 \mathrm{~nm}$ are still observed.

Electrochemistry. To evaluate how the peripheral sulfuration of one bpy ligand impacts the electronic properties of the $\mathrm{Ru}^{\mathrm{II}}$ complexes, detailed electrochemical studies on $\mathbf{1}^{2+}$ and $2^{2+}$ were performed. A glassy carbon working electrode was used, and all data were referenced versus the internal standard $\mathrm{Fc}^{+/ 0}$. The cyclic voltammetry $(\mathrm{CV})$ data of $\mathbf{1}^{2+}$ and $2^{2+}$ were recorded at $298 \mathrm{~K}$ in dry $\mathrm{CH}_{3} \mathrm{CN}$ containing $0.2 \mathrm{M}$ ${ }^{\mathrm{n}} \mathrm{Bu}_{4} \mathrm{NPF}_{6}$. Both complexes show a reversible redox couple at $E^{1 / 2}=+0.96\left(1^{2+}\right)$ and $+0.93 \mathrm{~V}\left(2^{2+}\right)$, which is assigned to the $\mathrm{Ru}^{\mathrm{II} / \mathrm{III}}$ oxidation (Table 3 and Figure S20) and is very similar to the value for parent $\left[\mathrm{Ru}(\mathrm{bpy})_{3}\right]^{2+21}$ indicating that the peripheral sulfuration exerts only a marginal effect on the central metal ion.

The CV data of $2^{2+}$ show reversible redox couples at $E^{1 / 2}=$ $-1.70,-1.89$, and $-2.13 \mathrm{~V}$ (Figure 5 and Table 3 ). The peak potentials do not shift with increasing scan rate, and the peakto-peak separation is close to the Nernstian value for a reversible redox process (Figure S21 shows scan rate dependent data). The potentials are almost identical to those of $\left[\mathrm{Ru}(\mathrm{bpy})_{3}\right]^{2+}$, indicative of consecutive ligand centered reductions. ${ }^{21}$ This suggests that ${ }^{S}$ bpy serves as a one electron acceptor, and the introduction of one sulfur atom does not significantly alter the electronic nature of the bpy ligand.
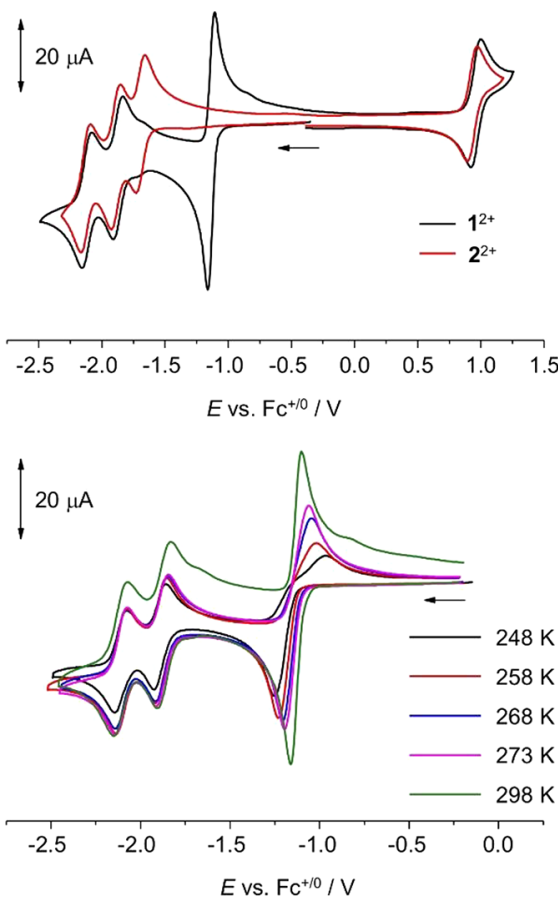

Figure 5. Top: CV data of $\mathbf{1}^{2+}$ and $\mathbf{2}^{2+}$ at RT. Bottom: temperaturedependent $\mathrm{CV}$ data of $1^{2+} ; \mathrm{CH}_{3} \mathrm{CN}, 0.2 \mathrm{M}^{\mathrm{n}} \mathrm{Bu}_{4} \mathrm{NPF}_{6}, \nu=0.1 \mathrm{~V} \mathrm{~s}^{-1}$.

In stark contrast, the first reduction peak for $\mathbf{1}^{2+}$ shows a remarkable anodic shift to $E_{\mathrm{pc}}=-1.16 \mathrm{~V}\left(\nu=0.1 \mathrm{~V} \mathrm{~s}^{-1}\right)$, whereas the formal potentials of the second and third reduction events are very similar to the corresponding ones in $2^{2+}$ and parent $\left[\mathrm{Ru}(\mathrm{bpy})_{3}\right]^{2+}$. This suggests a ${ }^{S-S}$ bpycentered reduction in the first process and bipyridine-centered reductions in the latter ones. The large current of the first reduction wave in the forward scan indicates that the process is actually a $2 \mathrm{e}^{-}$event, as was also observed for the free ${ }^{\mathrm{S}-\mathrm{S}}$ bpy ligand. 5 Indeed, estimation of the number of transferred electrons according to the Randles-Sevcik equation leads to $\sim 1.6$ electrons for the first reduction process (Figure S22). This indicates that reduction of $\mathbf{1}^{2+}$ yields $\mathbf{1}$ in which two adjacent thiolates are present. The peak potentials of the cathodic and anodic events for $\mathbf{1}^{2+}$ around $-1.1 \mathrm{~V}$ largely shift with increasing scan rate, and the large peak separation of the anodic and cathodic waves indicate that it is not a Nernstian $2 \mathrm{e}^{-}$event (Figure S23, Table S2). Similar ruthenium and osmium complexes with $\mathrm{RO}^{-}$functionalities instead of $\mathrm{RS}^{-}$, i.e., $\left[2,2^{\prime}\right.$-bipyridine $]-3,3^{\prime}$-bis(olate) instead of [2,2'-bipyridine]-3,3'-bis(thiolate), have been shown to be prone for protonation, ${ }^{27}$ and thus, we investigated whether the $2 \mathrm{e}^{-}$ reduction is coupled to proton transfer, e.g., due to traces of water. UV-vis-spectroelectrochemical (UV-vis-SEC) reduction of $1^{2+}$ at $-35^{\circ} \mathrm{C}$ leads to a new species with a pronounced absorption at $350 \mathrm{~nm}$ and visible bands at 440 and $500 \mathrm{~nm}$ (Figure S31). The redox process is fully reversible as the original UV-vis spectra are recovered after reoxidation. The same experiment at $-35{ }^{\circ} \mathrm{C}$ in the presence of 1 equiv of [Hdmf](OTf) leads to a reduced species with distinctly different absorption properties, namely, the species exhibits two bands at 440 and $470 \mathrm{~nm}$ and lacks the band at $350 \mathrm{~nm}$ (Figure S32). The process is also fully reversible as reoxidation establishes $\mathbf{1}^{2+}$. This suggests that reduction in the former experiment is not coupled to a proton transfer, as protonation is typically associated with a blue shift of the MLCT bands in 
Table 3. Half Peak Potentials $\left(E^{1 / 2}\right)$ and Peak Potentials $\left(E_{\mathrm{p}}\right)$ at $0.1 \mathrm{Vs}^{-1}$ for $1^{2+}, 2^{2+}$, and $\left[\mathrm{Ru}(\mathrm{bpy})_{3}\right]^{2+}$ in Acetonitrile at 298 $\mathbf{K}^{a}$

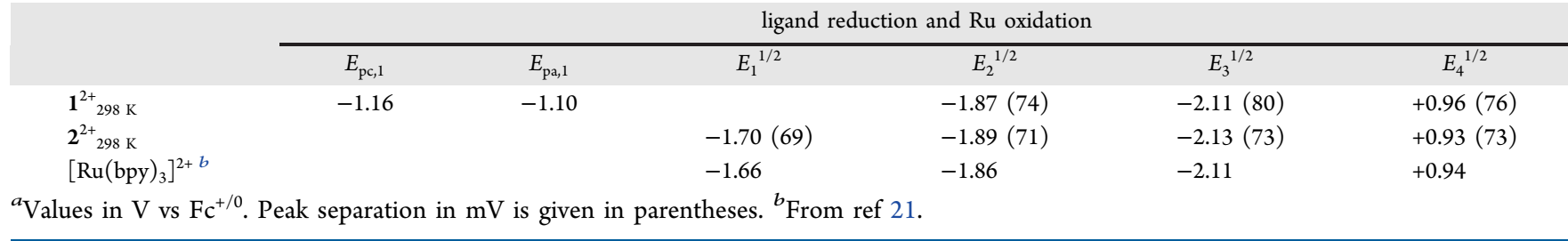

the visible region and of the IL (intra ligand) band at $350 \mathrm{~nm}$ in 1 since bpy $(\mathrm{SH})\left(\mathrm{S}^{-}\right)$is a weaker $\mathrm{CT}$ acceptor than bpy $\left(\mathrm{S}^{-}\right)_{2} \cdot{ }^{28}$ Chemical reduction with 2 equiv of cobaltocene ${ }^{29}$ leads to the same species as electrochemical reduction, and the addition of two equivalents of the strong base 1,8diazabicyclo[5.4.0] undec-7-en $\left(\mathrm{pK}_{\mathrm{a}}=24.34 \text { in } \mathrm{CH}_{3} \mathrm{CN}\right)^{30}$ does not lead to any changes in the UV-vis spectra, whereas addition of 1 equiv of [Hdmf](OTf) results in the same species as in the electrochemical experiment in the presence of protons (Figure S19). These experiments suggest that reduction in anhydrous $\mathrm{CH}_{3} \mathrm{CN}$ in the absence of added proton source is not coupled to proton transfer and that a neutral species 1 with a dianionic bpy $\left(\mathrm{S}^{-}\right)_{2}$ ligand is obtained after two-electron reduction in $\mathrm{CH}_{3} \mathrm{CN}$ (Scheme 2).

Scheme 2. $2 \mathrm{e}^{-}$Reduction of Disulfide Complex $1^{2+}$ to Give Dithiolate Complex 1 and Subsequent Conversion to $2^{2+a}$

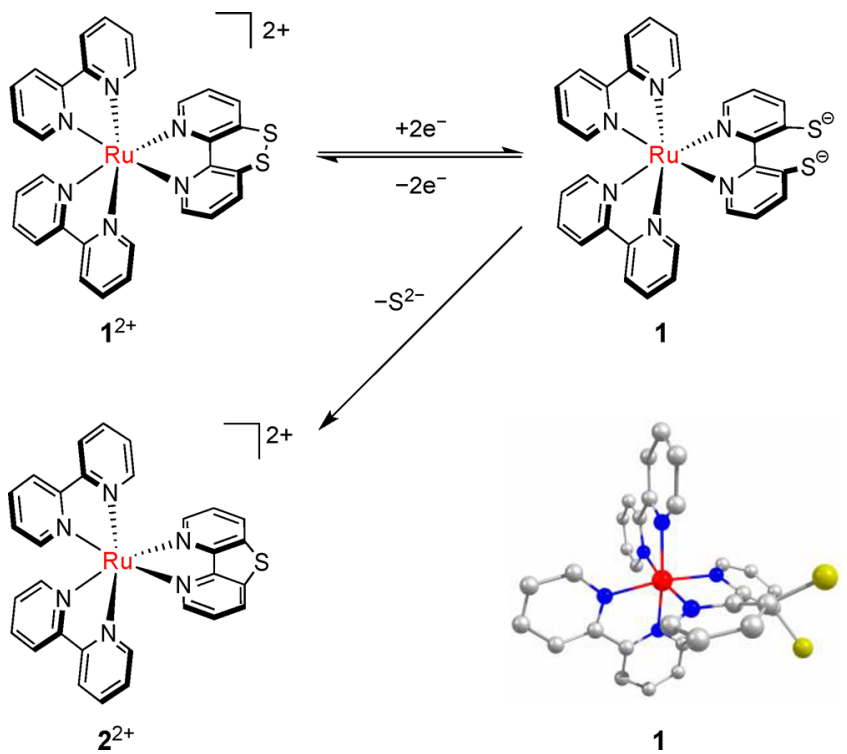

${ }^{a}$ The DFT optimized structure of $\mathbf{1}$ is shown in the lower right (red, $\mathrm{Ru}$; blue, N; yellow, S; grey, C; see SI for details).

In the $\mathrm{CV}$ trace of $\mathbf{1}^{2+}$, after initial reduction, a small oxidation peak appears in the reverse scan at $-1.70 \mathrm{~V}$ at slow scan rates, e.g., $<0.1 \mathrm{~V} \mathrm{~s}^{-1}$. The peak potential matches the one for the anodic feature in the reverse scan after the first reduction of $2^{2+}$, which suggests that $1^{2+}$ transforms into $2^{2+}$ under reductive conditions (Scheme 2 ). Indeed, coulometry at an applied potential of $-1.25 \mathrm{~V}$ leads to full conversion of $\mathbf{1}^{2+}$ into $2^{2+}$ (Figure S24). Such facile elimination of one sulfur atom from a disulfide moiety was previously observed for diaromatic disulfide compounds, where the decomposition of the disulfide bridge is triggered by heating. ${ }^{6 \mathrm{~b}}$ Our previous study of free ${ }^{S-S}$ bpy revealed that $S-S$ bond breaking and rotation around the central $\mathrm{C}-\mathrm{C}$ bond of the bipyridine unit occurs after the second reduction step. ${ }^{5}$ However, as the ${ }^{S}-\mathrm{S}$ bpy ligand coordinates to the metal ion, rotation of the two pyridine units upon injecting the electrons is restricted in $\mathbf{1}^{2+}$. Thus, the accumulation of negative charges in close proximity in combination with the nucleophilic character of thiolates might induce the elimination of a sulfide ion. The CV feature attributed to $2^{2+}$ vanishes upon increasing the scan rates $(\nu>$ $0.5 \mathrm{~V} \mathrm{~s}^{-1}$, see Figure S23), indicating that the chemical reaction rate constant for sulfide extrusion is on the order of $0.05 \mathrm{~s}^{-1}$.

In order to slow down the transformation of the ${ }^{\mathrm{S}-\mathrm{S}} \mathrm{bpy}$ into the ${ }^{S}$ bpy ligand upon reduction of $\mathbf{1}^{2+}, \mathrm{CV}$ data were recorded at lower temperatures (Figure S26). Below $273 \mathrm{~K}$, no decomposition was observed on the time scale of the experiment at $0.1 \mathrm{~V} \mathrm{~s}^{-1}$. However, the oxidative features of the initial $2 \mathrm{e}^{-}$reduction process change significantly with decreasing temperature, most strikingly in the reverse scan. As temperature decreases, the cathodic peak potential shifts to more negative potentials, while the anodic peak broadens and shifts to higher potentials; thus, the peak-to-peak separation increases (Figure 5, bottom). These findings can be attributed to slower electron-transfer rates at lower temperatures. Therefore, simulation of the $\mathrm{CV}$ data was pursued to extract thermodynamic and kinetic information.

The four reduction processes of $\mathbf{1}^{2+}$ were simulated utilizing $\mathrm{CV}$ data over a large scan rate range from 0.1 to $10 \mathrm{~V} \mathrm{~s}^{-1}$, applying a Butler-Volmer model. ${ }^{31}$ Representative experimental data and fits are presented in Figure 6. Further figures showing the other scan rates at various temperatures can be found in the Supporting Information (Figure S28).

Good simulations were achieved using reasonable values for the various parameters over the full sweep rate range (Table 4). The large cathodic current and the rather broad reverse peak of the first feature, reflected by the $i_{\mathrm{pc}}$ over $i_{\mathrm{pa}}$ ratio, indicates an $\alpha$ value above $0.5 ; \alpha$ for $E_{1}$ and $E_{2}$ were set to 0.7 . The steep slope of the first process indicates potential inversion, meaning that the initial reduction facilitates the subsequent reduction process. ${ }^{32}$ Indeed, on the basis of the simulations, the potential of the second reduction process is always less negative than the potential of the first process, irrespective of the temperature (Table 4$)$. In free ${ }^{\mathrm{S}-\mathrm{S}}$ bpy, the second reduction appeared at lower potentials than the first one (cf. $E_{1}=-1.20 \mathrm{~V}$ and $\left.E_{2}=-1.38 \mathrm{~V}\right) .{ }^{5}$ Given that ${ }^{\mathrm{S}-\mathrm{S}}$ bpy is bound to a positively charged metal ion in $\mathbf{1}^{2+}$, the formal potential of the initial redox process is slightly higher than in free ${ }^{S-S}$ bpy. However, the geometric constraints after reduction of $\mathbf{1}^{2+}$ are much larger in comparison to free ${ }^{\mathrm{S}-\mathrm{S}}$ bpy as the two pyridine units cannot rotate freely around the central $\mathrm{C}-\mathrm{C}$ axis. Nevertheless, such a redox-triggered structural variation could facilitate the potential compression, as was reported for some $N$-aryl expanded pyridinium electrophores. ${ }^{33}$

Redox potentials may change with varying temperatures. ${ }^{34}$ Since $\Delta G$ equals $-n \cdot F \cdot E$, the change in the redox potential can 


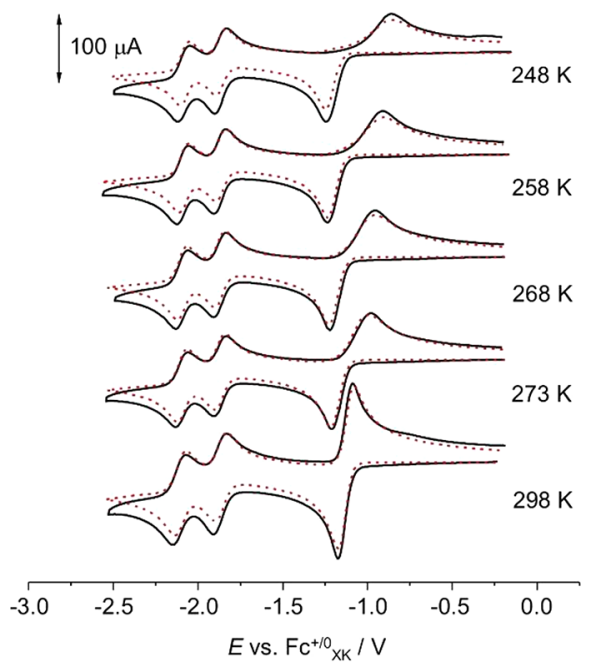

Figure 6. Experimental (black lines) and simulated (red dashed lines) $\mathrm{CV}$ data of $\mathbf{1}^{2+}$ in $\mathrm{CH}_{3} \mathrm{CN}$ at various temperatures, representative scan rate of $1 \mathrm{~V} \mathrm{~s}^{-1},\left[\mathbf{1}^{2+}\right]=0.98 \mathrm{mM}, 0.2 \mathrm{M}^{\mathrm{n}} \mathrm{Bu}_{4} \mathrm{NPF}_{6}$; parameters: see Table 4.

be related to change in entropy and enthalpy ( $n=$ number of electrons, $F=$ Faraday constant). These changes can be calculated from the slope $\partial E / \partial T$ as $\Delta S$ equals $-(\partial G / \partial T)_{\mathrm{p}}$ and $\Delta H$ equals $n F\left(T(\partial E / \partial T)_{\mathrm{p}}-E\right) .{ }^{35}$ However, since we determined $E^{\prime 0}$ versus the formal redox couple of ferrocene at the respective temperature, the experimentally observed potential shifts include the temperature dependence of the $\mathrm{Fc}^{+/ 0}$ couple, too. Thus, we corrected the potentials accordingly from temperature-dependent $\mathrm{CV}$ measurements of ferrocene (see the Supporting Information). ${ }^{36}$ A decrease of temperature has virtually no influence on the redox potential of the reversible reduction processes $E_{3}$ and $E_{4}$ of $\mathbf{1}^{2+}$. The potentials $E_{4}$ remain constant within a standard deviation of $\pm 3 \mathrm{mV}$ and the ones of $E_{3}$ within about $\pm 7 \mathrm{mV}$ standard deviation. The same is observed for $E_{1}$ and $E_{2}$, although the standard deviation is slightly larger for $E_{1}$, namely, $\pm 10 \mathrm{mV}$, and $\pm 6 \mathrm{mV}$ for $E_{2}$. However, none of the potentials follows a clear trend, which indicates that the changes in entropy and enthalpy upon reduction are likely small (Figure S29).

Subsequently, we had a closer look at the kinetics of the reductive electron-transfer processes. Electron-transfer rates for the first and the second reduction process, $E_{1}$ and $E_{2}$, strongly depend on the temperature. At $248 \mathrm{~K}$, the processes are both quasi-reversible, i.e., $k_{\mathrm{s}, 1}=4 \times 10^{-4} \mathrm{~cm} \mathrm{~s}^{-1}$ and $k_{\mathrm{s}, 2}=1.5 \times$ $10^{-3} \mathrm{~cm} \mathrm{~s}^{-1}$, whereas at $298 \mathrm{~K}$ both processes are reversible, i.e., $k_{\mathrm{s}, 1}=0.02 \mathrm{~cm} \mathrm{~s}^{-1}$ and $k_{\mathrm{s}, 2}=0.07 \mathrm{~cm} \mathrm{~s}^{-1}$ (Table 4). From the Arrhenius plot of $E_{1}$ and $E_{2}$, i.e., $\ln \left(k_{\mathrm{s}}\right)$ vs $1 / T$, the activation energy and the pre-exponential factor $A$ are estimated (Figure 7 ). ${ }^{37}$ The plot reveals very similar activation

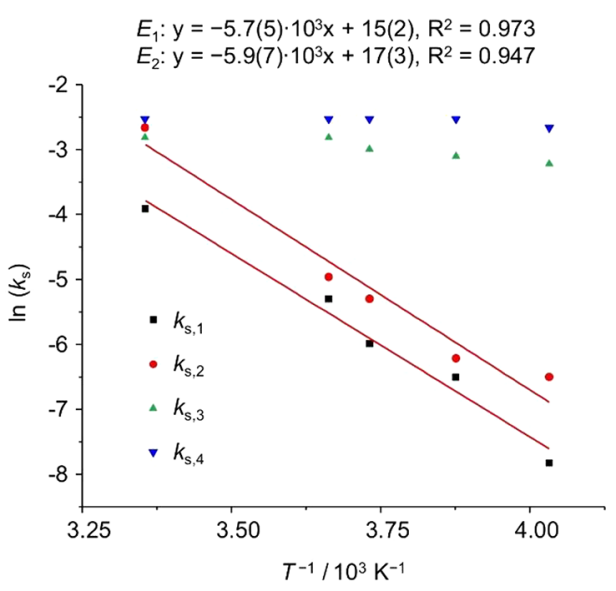

Figure 7. Arrhenius plot for the four sequential electron-transfer rates of $\mathbf{1}^{2+}$ in the temperature range from -25 to $+25{ }^{\circ} \mathrm{C}$. The red lines represent the linear fits.

Table 4. Thermodynamic and Kinetic Parameters Obtained from the Simulations of the CV Data for $1^{2+}$ at Various Temperatures. ${ }^{a}$

\begin{tabular}{|c|c|c|c|c|c|}
\hline$T(\mathrm{~K})$ & & $E_{1}$ & $E_{2}$ & $E_{3}$ & $E_{4}$ \\
\hline \multirow[t]{4}{*}{248} & $E^{\prime 0} \mathrm{vs} \mathrm{Fc}^{+/ 0}{ }_{248 \mathrm{~K}}(\mathrm{~V})$ & -1.120 & -1.065 & -1.865 & -2.080 \\
\hline & $E^{\prime 0}$ vs $\mathrm{Fc}^{+/ 0}{ }_{\mathrm{RT}}(\mathrm{V})$ & -1.140 & -1.085 & -1.885 & -2.100 \\
\hline & $k_{\mathrm{s}}\left(\mathrm{cm} \mathrm{s}^{-1}\right)$ & $4 \times 10^{-4}$ & $1.5 \times 10^{-3}$ & 0.04 & 0.07 \\
\hline & $\alpha$ & 0.7 & 0.7 & 0.5 & 0.5 \\
\hline \multirow[t]{4}{*}{258} & ${E^{\prime 0^{\prime} 0}}^{\mathrm{vs} \mathrm{Fe}^{+/ 0}}{ }_{258 \mathrm{~K}}(\mathrm{~V})$ & -1.140 & -1.080 & -1.865 & -2.085 \\
\hline & $E^{\prime 0}$ vs $\mathrm{Fc}^{+/ 0}{ }_{\mathrm{RT}}(\mathrm{V})$ & -1.160 & -1.100 & -1.885 & -2.105 \\
\hline & $k_{\mathrm{s}}\left(\mathrm{cm} \mathrm{s}^{-1}\right)$ & 0.0015 & 0.002 & 0.045 & 0.08 \\
\hline & $\alpha$ & 0.7 & 0.7 & 0.5 & 0.5 \\
\hline \multirow[t]{4}{*}{268} & $E^{\prime 0} \mathrm{vs} \mathrm{Fc}^{+/ 0}{ }_{268 \mathrm{~K}}(\mathrm{~V})$ & -1.145 & -1.075 & -1.870 & -2.095 \\
\hline & $E^{\prime 0}$ vs $\mathrm{Fc}^{+/ 0}{ }_{\mathrm{RT}}(\mathrm{V})$ & -1.160 & -1.090 & -1.885 & -2.110 \\
\hline & $k_{\mathrm{s}}\left(\mathrm{cm} \mathrm{s}^{-1}\right)$ & 0.0025 & 0.005 & 0.05 & 0.08 \\
\hline & $\alpha$ & 0.7 & 0.7 & 0.5 & 0.5 \\
\hline \multirow[t]{4}{*}{273} & $E^{\prime 0} \mathrm{vs} \mathrm{Fc}^{+/ 0}{ }_{273 \mathrm{~K}}(\mathrm{~V})$ & -1.155 & -1.080 & -1.870 & -2.095 \\
\hline & $E^{\prime 0} \mathrm{vs} \mathrm{Fc}_{\mathrm{RT}}^{+/ 0}(\mathrm{~V})$ & -1.165 & -1.090 & -1.880 & -2.105 \\
\hline & $k_{\mathrm{s}}\left(\mathrm{cm} \mathrm{s}^{-1}\right)$ & 0.005 & 0.007 & 0.06 & 0.08 \\
\hline & $\alpha$ & 0.7 & 0.7 & 0.5 & 0.5 \\
\hline \multirow[t]{3}{*}{298} & $E^{\prime 0} \mathrm{vs} \mathrm{Fc}^{+/ 0}{ }_{298 \mathrm{~K}}(\mathrm{~V})$ & -1.145 & -1.100 & -1.865 & -2.105 \\
\hline & $k_{\mathrm{s}}\left(\mathrm{cm} \mathrm{s}^{-1}\right)$ & 0.02 & 0.07 & 0.06 & 0.08 \\
\hline & $\alpha$ & 0.7 & 0.7 & 0.5 & 0.5 \\
\hline
\end{tabular}

${ }^{a} E$ vs. $\mathrm{Fc}^{+/ 0}$ XK denotes the formal redox potential versus the potential of $\mathrm{Fc}^{+/ 0}$ at the respective temperature $\mathrm{X}$, and $E$ vs. $\mathrm{Fc}^{+/ 0}{ }_{\mathrm{RT}}$ versus the potential of $\mathrm{Fc}^{+/ 0}$ at $298 \mathrm{~K}$. The values of $E$ were set with an accuracy of $\pm 5 \mathrm{mV}$. 
energies for both reduction processes, namely, 47 and $49 \mathrm{kcal}$ $\mathrm{mol}^{-1}$ for $E_{1}$ and $E_{2}$, respectively (Table 5). The pre-

Table 5. Activation Energies and Pre-exponential Factors for the Electron-Transfer Processes of $\mathbf{1}^{2+}$ According to the Arrhenius Equation. ${ }^{38}$

\begin{tabular}{ccc} 
& $E_{\mathrm{a}} / \mathrm{kJ} \mathrm{mol}^{-1}$ & $A / \mathrm{cm} \mathrm{s}^{-1}$ \\
$E_{1}$ & $47(4)$ & $3.9(0.3) \times 10^{6}$ \\
$E_{2}$ & $49(6)$ & $1.9(0.3) \times 10^{7}$ \\
\hline
\end{tabular}

exponential factors $A$ for $\mathbf{1}^{2+}$ are about 2 orders of magnitude larger than expected for outer sphere adiabatic electrontransfer reactions according to Marcus-Hush theory. ${ }^{38}$ This suggests a contribution of the inner sphere reorganization energy to $A$; that is, tilting of the ligand as well as elongation of the $S-S$ bond and finally bond rupture, since a bond rupture coupled to the electron-transfer processes leads to higher frequency factors. Indeed, the DFT optimized structure of 1 (Scheme 2) reveals an increase of the $\mathrm{C}-\mathrm{S} 1-\mathrm{S} 2-\mathrm{C}$ torsion angle from $56.71^{\circ}$ to $79.62^{\circ}$ upon two-electron reduction of $1^{2+}$, concomitant with lengthening of the $S \cdots S$ distance to 3.56 $\AA\left(2.05 \AA\right.$ in $\left.\mathbf{1}^{2+}\right)$. The pre-exponential factors are similar, which points to a rather smooth tilting of the ligand and S...S bond elongation over the two reduction processes. The electron-transfer rate of the third reduction process, $E_{3}$, indicates a reversible process over the entire temperature range; though, it depends slightly on the temperature (Figure S30). However, these small changes are within the error margins, and linearization of the data leads to low correlation and large errors for the slope and the intercept. The electrontransfer rate of the fourth reduction process, $E_{4}$, which is related to one of the bipyridine ligands, is essentially independent of temperature. The transfer rate of $0.08 \mathrm{~cm} \mathrm{~s}^{-1}$ is characteristic for a reversible process.

DFT Calculations of Electronic Excitations. The optical absorption properties of $\mathbf{1}^{2+}$ and $2^{2+}$ have been further characterized with the help of DFT/TD-DFT computations. As a validation of the computational method, we rely on the reasonably good agreement (RMSD $=0.263 \AA$ ) of the optimized geometries of both complexes with respect to $\mathrm{X}$ ray diffraction data (see relevant geometrical parameters in Table 1). Note however, a slight but systematic elongation of the $\mathrm{Ru}-\mathrm{N}$ bonds by $0.03-0.05 \AA$ in the calculated structures of both complexes. Additionally, the optimized geometries reveal that the two pyridine rings of the parent bpy ligands are perfectly coplanar, whereas they are slightly tilted toward each other in the crystallographically determined structures. Notably, the calculated disulfide $S-S$ bond length in $\mathbf{1}^{2+}$ is $2.106 \AA$, about $0.05 \AA$ longer than that in the crystal structure, while the calculated torsion angle $\mathrm{C}-\mathrm{S} 1-\mathrm{S} 2-\mathrm{C}$ is well reproduced. The Cartesian coordinates of the DFT optimized structures of $\mathbf{1}^{2+}$ and $\mathbf{2}^{2+}$ are given in the Supporting Information.

The electronic excited states calculated at the optimized geometries of $\mathbf{1}^{2+}$ and $\mathbf{2}^{2+}$ are listed in Table 6. For $\mathbf{1}^{2+}$, there are two states with large oscillator strengths, $S_{3}$ and $S_{9}$, at 2.64 $\mathrm{eV}(470 \mathrm{~nm})$ and $3.04 \mathrm{eV}(408 \mathrm{~nm})$, respectively. Interestingly, these excited states are representative of two blocks of excitations localized at different ligands; while $S_{3}$ is primarily an excitation from the Ru center toward the ${ }^{S-S}$ bpy ligand (MSCT), $\mathrm{S}_{9}$ is composed of two MLCT contributions originating from charge transfer from the $\mathrm{Ru}$ center to both
Table 6. Calculated Excited States of $1^{2+}$ and $2^{2+}$

\begin{tabular}{|c|c|c|c|}
\hline & \multicolumn{3}{|c|}{$1^{2+}$} \\
\hline & $\Delta E(\mathrm{eV})$ & $f_{\text {osc. }}$ (a.u.) & character \\
\hline $\mathrm{S}_{1}$ & 2.31 & 0.001 & MSCT \\
\hline $\mathrm{S}_{2}$ & 2.50 & 0.002 & MSCT \\
\hline $\mathrm{S}_{3}$ & 2.64 & 0.103 & MSCT \\
\hline $\mathrm{S}_{4}$ & 2.64 & 0.011 & $\mathrm{SC}$ \\
\hline $\mathrm{S}_{5}$ & 2.72 & 0.004 & MLCT \\
\hline $\mathrm{S}_{6}$ & 2.72 & 0.001 & MLCT \\
\hline $\mathrm{S}_{7}$ & 2.93 & 0.008 & MLCT \\
\hline $\mathrm{S}_{8}$ & 2.97 & 0.005 & MLCT \\
\hline $\mathrm{S}_{9}$ & 3.04 & 0.125 & MLCT \\
\hline \multirow[t]{3}{*}{$\mathrm{S}_{10}$} & 3.20 & 0.033 & MLCT \\
\hline & \multicolumn{3}{|c|}{$2^{2+}$} \\
\hline & $\Delta E(\mathrm{eV})$ & $f_{\text {osc. }}$ (a.u.) & character \\
\hline $\mathrm{S}_{1}$ & 2.69 & 0.000 & MSCT \\
\hline $\mathrm{S}_{2}$ & 2.72 & 0.002 & MLCT \\
\hline $\mathrm{S}_{3}$ & 2.73 & 0.001 & MLCT \\
\hline $\mathrm{S}_{4}$ & 2.88 & 0.003 & MLCT \\
\hline $\mathrm{S}_{5}$ & 2.89 & 0.035 & MLCT \\
\hline $\mathrm{S}_{6}$ & 2.90 & 0.006 & MLCT/MSCT \\
\hline $\mathrm{S}_{7}$ & 2.98 & 0.104 & MSCT/MLCT \\
\hline $\mathrm{S}_{8}$ & 3.03 & 0.134 & MLCT \\
\hline $\mathrm{S}_{9}$ & 3.22 & 0.002 & MLCT \\
\hline$S_{10}$ & 3.54 & 0.001 & MC \\
\hline
\end{tabular}

bpy ligands (shown as NTOs in Figure 8). Such electronic structure offers an interesting opportunity for steering the direction of electron transfer at low or high excitation energies, either to the disulfide bridged ${ }^{S-S}$ bpy or toward one (or both) of the unsubstituted bpy ligands, respectively. Charge transfer from any of the ligands toward the metal is found to be unlikely.

A more realistic description of the lowest-energy band of both absorption spectra is obtained by including nuclear vibrational motion via a harmonic Wigner ensemble of 200 geometries. As shown in Figure 9a,b, the calculated spectra are in excellent agreement with the experimental ones. Both spectra have been decomposed into contributions from the different types of excitations. The experimental absorption spectrum of $1^{2+}$ shows a peak at $435 \mathrm{~nm}$ with a low-energy shoulder below $500 \mathrm{~nm}$. The decomposition of the spectrum reveals that the high-energy peak is dominated by chargetransfer processes toward the bpy ligands (MLCT), while the low-energy shoulder mainly originates from charge transfer toward the ${ }^{S-S}$ bpy (denoted MSCT), with only minor contributions from MLCT processes. These results reinforce the interpretation based on the optimized geometry that the ability to stabilize the electron at the ${ }^{\mathrm{S}-\mathrm{S}}$ bpy ligand results in a red shift of the corresponding states, leading to the observed shoulder in the experimental absorption spectrum. The energetic separation of excitations toward the ${ }^{S-S}$ bpy or bpy ligands (MSCT and MLCT) holds upon including vibrational sampling. When comparing the position of the calculated absorption maxima with the excitation energies of the two states with large oscillator strengths at the optimized geometry, a red shift of about $20 \mathrm{~nm}$ is observed. In passing, we note that the low-energy MSCT shoulder at $500 \mathrm{~nm}$ is only present due to the solvent, as calculations in the gas phase (not shown) place the contribution of the MSCT states blue-shifted to 460 


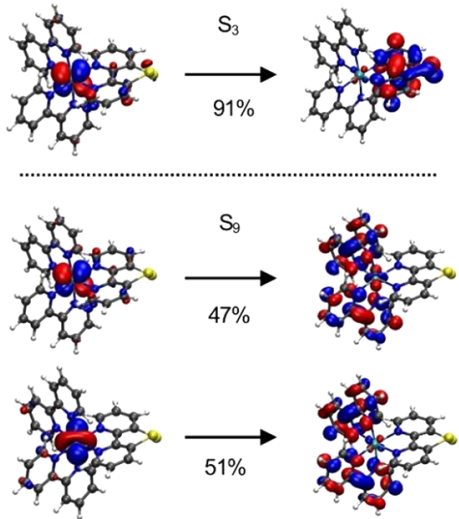

$1^{2+}$
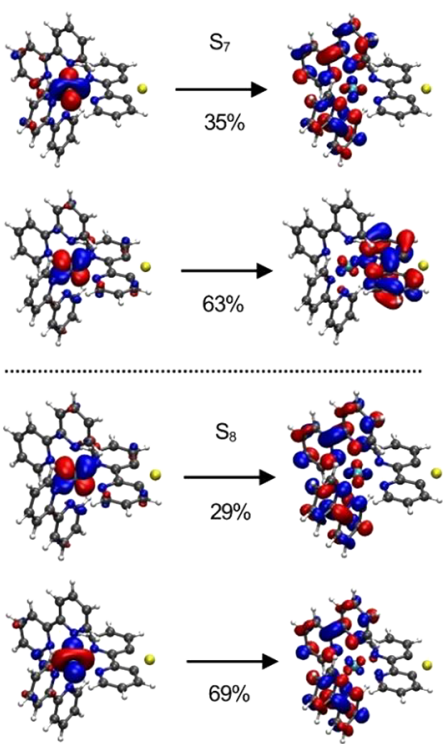

$2^{2+}$

Figure 8. NTOs of the two states with large oscillator strengths $S_{3}$ and $S_{9}$ of $\mathbf{1}^{2+}$ and $S_{7}$ and $S_{8}$ of $\mathbf{2}^{2+}$. The contribution of the transition to the excited state is given below the corresponding arrow.

\begin{tabular}{|lllll|}
\hline$\overline{\mathrm{MC}}$ & $\overline{\mathrm{LC}}$ & $\overline{\mathrm{MLCT}}$ & $\overline{\mathrm{LC} T}$ & $\overline{\mathrm{LCT}}$ \\
$\overline{\mathrm{SC}}$ & $\overline{\mathrm{SLC} T}$ & $\mathrm{MSC}$ & $\overline{\mathrm{SMC} T}$ & $\overline{\mathrm{LSC} T}$ \\
\hline
\end{tabular}

(a)

(b)

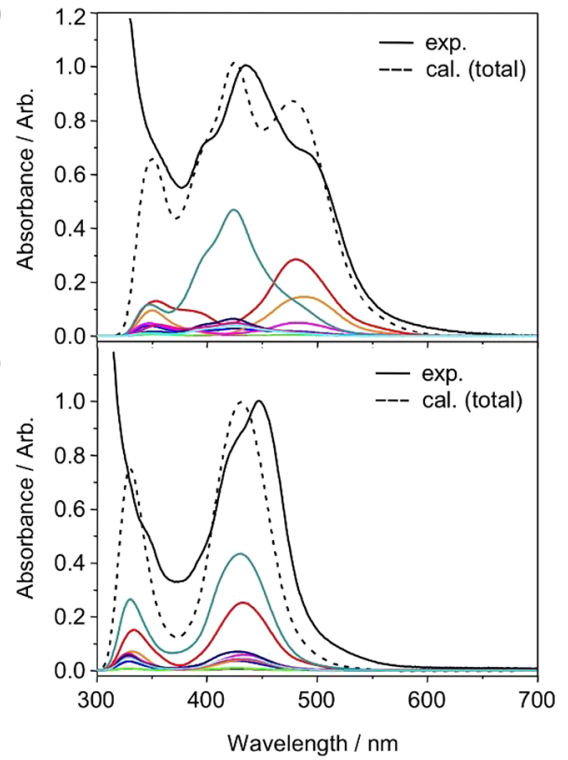

(c)

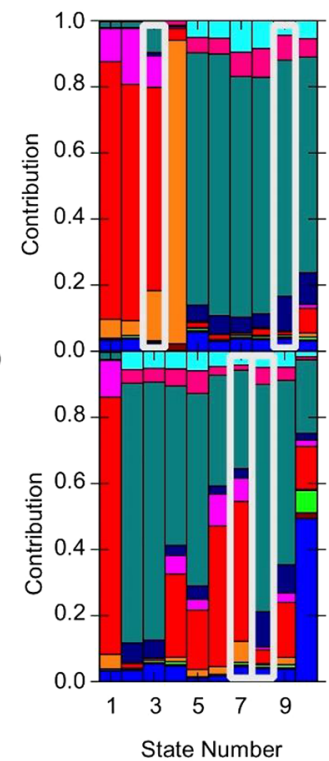

(e)

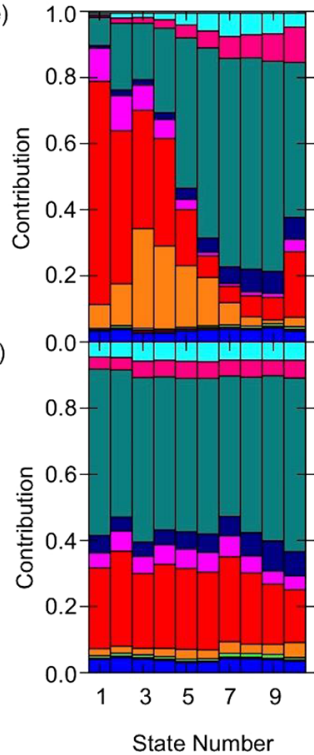

Figure 9. Calculated absorption spectra of $\mathbf{1}^{2+}$ (a) and $\mathbf{2}^{2+}$ (b) based on a harmonic Wigner ensemble. The spectra are decomposed into the different contributions to the absorbing states. Panels (c) and (d) show bar histograms of the different character contribution of each electronic singlet state at the optimized geometry based on charge-transfer numbers (see also Table 6). Gray boxes indicate states with large oscillator strengths. Panels (e) and (f) show the averaged charge-transfer character obtained from the Wigner ensemble. Color codes for the different types of excitations are given in the top part of the figure.

nm, strongly overlapping with the MLCT band, which is unshifted.

The experimental spectrum of $2^{2+}$ exhibits two maxima in close proximity within the MLCT region. The calculated absorption maximum is slightly blue-shifted with respect to the experimental absorption peak. Decomposition of the spectrum indicates that excitations from the $\mathrm{Ru}$ center toward all three ligands contribute equally to the absorption. Similar to $\mathbf{1}^{2+}$, a red shift of the absorption maxima with respect to the excitation energies of the bright states is observed.

The character of the first low-lying ten excited states of $\mathbf{1}^{2+}$ (panels $\mathrm{c}$ and e) and $\mathbf{2}^{2+}$ (panels $\mathrm{d}$ and $\mathrm{f}$ ) at the optimized geometry and within the average ensemble including nuclear motion, respectively, is shown in Figure 9. The separation between the low-lying excitations located at the ${ }^{\mathrm{S}-\mathrm{S}}$ bpy ligand from the other MLCT states that follow at higher energies is evident at the optimized geometry of $\mathbf{1}^{2+}$ (panel c), while no 
clear separation is visible for $\mathbf{2}^{2+}$ (panel $\mathrm{d}$ ). The inclusion of nuclear motion (panels e and f) entails mixing of MSCT and MLCT characters, highlighting the importance of the vibrational zero-point energy. However, one can appreciate a dominance of the MSCT band at lower energies and MLCT at high energies in $\mathbf{1}^{2+}$ (panel e), while MSCT and MLCT completely overlap in $\mathbf{2}^{2+}$ (panel f).

\section{CONCLUSION}

In summary, we have presented here a new $\left[\mathrm{Ru}(\mathrm{bpy})_{3}\right]^{2+}$-type photosensitizer $\mathbf{1}^{2+}$ equipped with a disulfide bridge at the backside of one bipyridine ligand. An important feature is that the ${ }^{S-S}$ bpy ligand can serve as a two-electron acceptor associated with the disulfide/ditholate redox pair. From thorough electrochemical characterization of $\mathbf{1}^{2+}$ in combination with simulation of the $\mathrm{CV}$ traces, it can be concluded that the ${ }^{S-S}$ bpy ligand is reduced first and at much less negative potentials than the parent bpy ligands, and that it undergoes a two-electron reduction with potential inversion; the electron transfer is kinetically controlled. The activation energies for both reduction processes are almost identical, indicating a smooth transition for the uptake of two electrons. Furthermore, the reduction of ${ }^{S-S}$ bpy at room temperature triggers ligand decomposition by $S$-extrusion, resulting in the rapid formation of $2^{2+}$. This transformation can be suppressed on the $\mathrm{CV}$ time scale by lowering the temperature. Comparing the UV-vis spectra of $1^{2+}, 2^{2+}$, and $\left[\mathrm{Ru}(\mathrm{bpy})_{3}\right]^{2+}$ reveals that $\mathbf{1}^{2+}$ features an additional low-energy absorption in the MLCT region at around $500 \mathrm{~nm}$. TD-DFT calculations show that the presence of the disulfide substituent in $\mathbf{1}^{2+}$ leads to a stabilization of charge-transfer excitations toward the ${ }^{S-S}$ bpy ligand (MSCT). The splitting in energy between the absorption maxima of excitations toward the ${ }^{S-S}$ bpy and the bpy ligands is about $2700 \mathrm{~cm}^{-1}$, offering the possibility of selectively exciting charge transfer into either of the two types of ligands. This could trigger different excited-state dynamics and opens up the road for targeted electron transfer. Such energy splitting between the different excitations is absent in $2^{2+}$ where excitations toward the ${ }^{S}$ bpy and bpy ligands are almost iso-energetic. While this distinct behavior starts to be apparent from the NTOs of the specific states of $\mathbf{1}^{2+}$ and $2^{2+}$ calculated at the optimized geometry, the inclusion of vibrational nuclear motion clearly pinpoints the onset and end of the respective MSCT and MLCT bands, which in $\mathbf{1}^{2+}$ are energetically separated and in $2^{2+}$ overlap. The MLCT luminescence of $\mathbf{1}^{2+}$ is phosphorescent in nature, with a lifetime of $109 \mathrm{~ns}$. In contrast, $\mathbf{2}^{2+}$ is not photostable and irradiation of $2^{2+}$ leads to dissociation of the ${ }^{\mathrm{S}}$ bpy ligand.

It should be noted here that the design principle of $\mathbf{1}^{2+}$ offers interesting prospects. First, this new $\left[\mathrm{Ru}(\mathrm{bpy})_{3}\right]^{2+}$ derivative $\mathbf{1}^{2+}$ is able to accommodate two electrons on the sulfurated bpy-type chelate ligand of the photosensitizer. After photoexcitation, this complex could potentially mediate two-electron two-proton conversions involving the peripheral disulfide/ dithiol switch, which might enable novel excited-state PCET chemistry and light-driven multielectron transformations. Second, the peripheral disulfide/dithiol functionality of S-S bpy can be exploited for anchoring the $\left[\mathrm{Ru}(\mathrm{bpy})_{3}\right]^{2+}$ photosensitizers onto, e.g., gold surfaces, or for directly attaching it to catalytically active metal complexes. Work in both directions is ongoing in our laboratories.

\section{ASSOCIATED CONTENT}

\section{(s) Supporting Information}

The Supporting Information is available free of charge at https://pubs.acs.org/doi/10.1021/acs.inorgchem.0c00220.

Figures of ESI-MS spectra, NMR spectra, IR spectra, $\mathrm{UV}-$ vis absorption and normalized photoluminescence spectra, luminescence decay curves, transient absorption spectra, CV data, redox couple plots, diffusion coefficients, temperature dependency, and optimized structures, tables of excited-state luminescence lifetimes, peak potentials, redox potentials, measured and calculated diffusion coefficients, and X-ray crystallographic data, and discussions of UV-vis experiments, Randles-Sevcik equation, temperature-dependent CV data, simulation of the CV data, X-ray crystallography, DFT calculations, and Cartesian coordinates (PDF)

\section{Accession Codes}

CCDC 1979158-1979159 contain the supplementary crystallographic data for this paper. These data can be obtained free of charge via www.ccdc.cam.ac.uk/data_request/cif, or by emailing data_request@ccdc.cam.ac.uk, or by contacting The Cambridge Crystallographic Data Centre, 12 Union Road, Cambridge CB2 1EZ, UK; fax: +44 1223336033.

\section{AUTHOR INFORMATION}

\section{Corresponding Authors}

Inke Siewert - University of Göttingen, Institute of Inorganic Chemistry, D-37077 Göttingen, Germany; 다이.org/00000003-3121-3917; Email: inke.siewert@chemie.unigoettingen.de

Leticia González - Institute of Theoretical Chemistry, Faculty of Chemistry, University of Vienna, A-1090 Vienna, Austria; ○ orcid.org/0000-0001-5112-794X; Email: leticia.gonzalez@univie.ac.at

Franc Meyer - University of Göttingen, Institute of Inorganic Chemistry, D-37077 Göttingen, Germany; (1) orcid.org/00000002-8613-7862; Email: franc.meyer@chemie.unigoettingen.de

\section{Authors}

Shao-An Hua - University of Göttingen, Institute of Inorganic Chemistry, D-37077 Göttingen, Germany

Mauricio Cattaneo - University of Göttingen, Institute of Inorganic Chemistry, D-37077 Göttingen, Germany

Manuel Oelschlegel - University of Göttingen, Institute of Inorganic Chemistry, D-37077 Göttingen, Germany

Moritz Heindl - Institute of Theoretical Chemistry, Faculty of Chemistry, University of Vienna, A-1090 Vienna, Austria

Lucius Schmid - Department of Chemistry, University of Basel, CH-4056 Basel, Switzerland

Sebastian Dechert - University of Göttingen, Institute of Inorganic Chemistry, D-37077 Göttingen, Germany

Oliver S. Wenger - Department of Chemistry, University of Basel, CH-4056 Basel, Switzerland; () orcid.org/0000-00020739-0553

Complete contact information is available at:

https://pubs.acs.org/10.1021/acs.inorgchem.0c00220

\section{Author Contributions}

The manuscript was written through contributions of all authors. 


\section{Funding}

F.M. and L.G. are grateful to the DFG for financial support of this work (projects Me1313/15-1 and Go1059/8-1 within the SPP 2102 "Light-Controlled Reactivity of Metal Complexes"). Initially this project was supported by the Alexander von Humboldt Foundation (postdoctoral fellowship for M.C.). O.S.W. acknowledges funding from the Swiss National Science Foundation through grant number 200021_178760.

\section{Notes}

The authors declare no competing financial interest.

\section{ACKNOWLEDGMENTS}

L.G. is grateful to the Göttingen Academy of Sciences for awarding a Gauss Professorship that allowed for an extended research stay in Göttingen. M.C. is member of the Research Career (CONICET, Argentina). L.G. also thanks the Vienna Scientific Cluster for allocation of computer time.

\section{REFERENCES}

(1) (a) Hammes-Schiffer, S. Theory of Proton-Coupled Electron Transfer in Energy Conversion Processes. Acc. Chem. Res. 2009, 42, 1881-1889. (b) Warren, J. J.; Tronic, T. A.; Mayer, J. M. Thermochemistry of Proton-Coupled Electron Transfer Reagents and Its Implications. Chem. Rev. 2010, 110, 6961-7001.

(2) (a) Gagliardi, C. J.; Westlake, B. C.; Kent, C. A.; Paul, J. J.; Papanikolas, J. M.; Meyer, T. J. Integrating Proton Coupled Electron Transfer (PCET) and Excited States. Coord. Chem. Rev. 2010, 254, 2459-2471. (b) Hammes-Schiffer, S. Proton-Coupled Electron Transfer: Moving Together and Charging Forward. J. Am. Chem. Soc. 2015, 137, 8860-8871. (c) Lennox, J. C.; Kurtz, D. A.; Huang, T.; Dempsey, J. L. Excited-State Proton-Coupled Electron Transfer: Different Avenues for Promoting Proton/Electron Movement with Solar Photons. ACS Energy Lett. 2017, 2, 1246-1256. (d) Pannwitz, A.; Wenger, O. S. Proton-coupled Multi-Electron Transfer and Its Relevance for Artificial Photo Synthesis and Photoredox Catalysis. Chem. Commun. 2019, 55, 4004-4014. (e) Wenger, O. S. ProtonCoupled Electron Transfer with Photoexcited Metal Complexes. Acc. Chem. Res. 2013, 46, 1517-1526. (f) Wenger, O. S. Proton-Coupled Electron Transfer with Photoexcited Ruthenium (II), Rhenium (I), and Iridium (III) Complexes. Coord. Chem. Rev. 2015, 282, 150-158. (3) (a) Pellegrin, Y.; Odobel, F. Molecular Devices Featuring Sequential Photoinduced Charge Separations for the Storage of Multiple Redox Equivalents. Coord. Chem. Rev. 2011, 255, 25782593. (b) Hammarstrom, L. Accumulative Charge Separation for Solar Fuels Production: Coupling Light-Induced Single Electron Transfer to Multielectron Catalysis. Acc. Chem. Res. 2015, 48, 840850. (c) Konduri, R.; Ye, H.; MacDonnell, F. M.; Serroni, S.; Campagna, S.; Rajeshwar, K. Ruthenium Photocatalysts Capable of Reversibly Storing up to Four Electrons in a Single Acceptor Ligand: A Step Closer to Artificial Photosynthesis. Angew. Chem., Int. Ed. 2002, 41, 3185-3187. (d) Konduri, R.; de Tacconi, N. R.; Rajeshwar, K.; MacDonnell, F. M. Multielectron Photoreduction of a Bridged Ruthenium Dimer, $\left[(\text { phen })_{2} \mathrm{Ru}(\right.$ tatpp $\left.) \mathrm{Ru}(\text { phen })_{2}\right]\left[\mathrm{PF}_{6}\right]_{4}$ : Aqueous Reactivity and Chemical and Spectroelectrochemical Identification of the Photoproducts. J. Am. Chem. Soc. 2004, 126, 11621-11629. (e) Chiorboli, C.; Fracasso, S.; Scandola, F.; Campagna, S.; Serroni, S.; Konduri, R.; MacDonnell, F. M. Primary Charge Separation in Photoinduced Multielectron Storage Systems. A Dinuclear Ruthenium (ii) Species Featuring a Charge-Separated State with a Lifetime of $1.3 \mu$ s. Chem. Commun. 2003, 1658-1659.

(4) (a) Nomrowski, J.; Wenger, O. S. Exploiting Potential Inversion for Photoinduced Multielectron Transfer and Accumulation of Redox Equivalents in a Molecular Heptad. J. Am. Chem. Soc. 2018, 140, 5343-5346. (b) Kuss-Petermann, M.; Orazietti, M.; Neuburger, M.; Hamm, P.; Wenger, O. S. Intramolecular Light-Driven Accumulation of Reduction Equivalents by Proton-Coupled Electron Transfer. J. Am. Chem. Soc. 2017, 139, 5225-5232. (c) Mendes Marinho, S.; Ha-
Thi, M. H.; Pham, V. T.; Quaranta, A.; Pino, T.; Lefumeux, C.; Chamaille, T.; Leibl, W.; Aukauloo, A. Time-Resolved Interception of Multiple-Charge Accumulation in a Sensitizer-Acceptor Dyad. Angew. Chem., Int. Ed. 2017, 56, 15936-15940. (d) Karlsson, S.; Boixel, J.; Pellegrin, Y.; Blart, E.; Becker, H. C.; Odobel, F.; Hammarstrom, L. Accumulative Charge Separation Inspired by Photosynthesis. J. Am. Chem. Soc. 2010, 132, 17977-17979. (e) O'Neil, M. P.; Niemczyk, M. P.; Svec, W. A.; Gosztola, D.; Gaines, G. L.; Wasielewski, M. R. Picosecond Optical Switching based on Biphotonic Excitation of an Electron Donor-Acceptor-Donor Molecule. Science 1992, 257, 63-65. (f) Orazietti, M.; Kuss-Petermann, M.; Hamm, P.; Wenger, O. S. Light-Driven Electron Accumulation in a Molecular Pentad. Angew. Chem., Int. Ed. 2016, 55, 9407-9410.

(5) Cattaneo, M.; Schiewer, C. E.; Schober, A.; Dechert, S.; Siewert, I.; Meyer, F. 2,2'-Bipyridine Equipped with a Disulfide/Dithiol Switch for Coupled Two-Electron and Two-Proton Transfer. Chem. - Eur. J. 2018, 24, 4864-4870.

(6) (a) Hall, G. B.; Kottani, R.; Felton, G. A.; Yamamoto, T.; Evans, D. H.; Glass, R. S.; Lichtenberger, D. L. Intramolecular Electron Transfer in Bipyridinium Disulfides. J. Am. Chem. Soc. 2014, 136, 4012-4018. (b) Benniston, A. C.; Hagon, J.; He, X.; Yang, S.; Harrington, R. W. Spring Open Two-Plus-Two Electron Storage in a Disulfide-Strapped Methyl Viologen Derivative. Org. Lett. 2012, 14, 506-509. (c) Benniston, A. C.; Allen, B. D.; Harriman, A.; Llarena, I.; Rostron, J. P.; Stewart, B. Accessing Molecular Memoryvia a Disulfide Switch. New J. Chem. 2009, 33, 417-427. (d) Nomrowski, J.; Guo, X.; Wenger, O. S. Charge Accumulation and Multi-Electron Photoredox Chemistry with a Sensitizer-Catalyst-Sensitizer Triad. Chem. - Eur. J. 2018, 24, 14084-14087.

(7) Al-Rawashdeh, N. A.; Chatterjee, S.; Krause, J. A.; Connick, W. B. Ruthenium Bis-Diimine Complexes with a Chelating Thioether Ligand: Delineating 1,10-Phenanthrolinyl and 2,2'-Bipyridyl Ligand Substituent Effects. Inorg. Chem. 2014, 53, 294-307.

(8) Favier, I.; Duñach, E. New Protic Salts of Aprotic Polar Solvents. Tetrahedron Lett. 2004, 45, 3393-3395.

(9) (a) Becke, A. Density-Functional Thermochemistry: The Role of Extract Exchange. J. Chem. Phys. 1993, 98, 5648-5652. (b) Lee, C.; Yang, W.; Parr, R. G. Development of the Colle-Salvetti CorrelationEnergy Formula into a Functional of the Electron Density. Phys. Rev. B: Condens. Matter Mater. Phys. 1988, 37, 785.

(10) Hay, P. J.; Wadt, W. R. Ab Initio Effective Core Potentials for Molecular Calculations. Potentials for the Transition Metal StomsSc to Hg. J. Chem. Phys. 1985, 82, 270-283.

(11) Grimme, S.; Antony, J.; Ehrlich, S.; Krieg, H. A Consistent and Accurate Ab Initio Parametrization of Density Functional Dispersion Correction (DFT-D) for the 94 Elements H-Pu. J. Chem. Phys. 2010, 132, 154104.

(12) Hess, B. A. Relativistic Electronic-Structure Calculations Employing a Two-Component No-Pair Formalism with ExternalField Projection Operators. Phys. Rev. A: At., Mol., Opt. Phys. 1986, 33, 3742.

(13) Cances, E.; Mennucci, B.; Tomasi, J. A New Integral Equation Formalism for the Polarizable Continuum Model: Theoretical Background and Applications to Isotropic and Anisotropic Dielectrics. J. Chem. Phys. 1997, 107, 3032-3041.

(14) (a) Casida, M. E.; Jamorski, C.; Casida, K. C.; Salahub, D. R. Molecular Excitation Energies to High-Lying Bound States from Time-Dependent Density-Functional Response Theory: Characterization and Correction of the Time-Dependent Local Density Approximation Ionization Threshold. J. Chem. Phys. 1998, 108, 4439-4449. (b) Runge, E.; Gross, E. K. Density-Functional Theory for Time-Dependent Systems. Phys. Rev. Lett. 1984, 52, 997.

(15) Martin, R. L. Natural Transition Orbitals. J. Chem. Phys. 2003, $118,4775-4777$.

(16) Frisch, M. J.; Trucks, G.; Schlegel, H.; Scuseria, G.; Robb, M.; Cheeseman, J.; Scalmani, G.; Barone, V.; Mennucci, B.; Petersson, G. et al. Gaussian 09 Revision D.01; Gaussian. Inc.: Wallingford, CT, 2009. 
(17) Crespo-Otero, R.; Barbatti, M. Spectrum Simulation and Decomposition with Nuclear Ensemble: Formal Derivation and Application to Benzene, Furan and 2-Phenylfuran. Theor. Chem. Acc. 2012, 131, 1237.

(18) Mai, S.; Plasser, F.; Dorn, J.; Fumanal, M.; Daniel, C.; Gonzalez, L. Quantitative Wave Function Analysis for Excited States of Transition Metal Complexes. Coord. Chem. Rev. 2018, 361, 74-97.

(19) Plasser, F. Theo DORE: APackage for Theoretical Density, Orbital Relaxation, and Exciton Analysis. Available at http:// theodore-qc.sourceforge.net/.

(20) Klemm, L.; McCoy, D.; Klopfenstein, C. Condensed Thiophenes from Sulfur Bridging. II. Catalyzed Reaction of Azabiaryls with Hydrogen Sulfide. J. Heterocycl. Chem. 1971, 8, 383-389.

(21) Heuer, W. B.; Xia, H. L.; Ward, W.; Zhou, Z.; Pearson, W. H.; Siegler, M. A.; NarducciSarjeant, A. A.; Abrahamsson, M.; Meyer, G. J. New Dicarboxylic Acid BipyridineLigand for Ruthenium PolypyridylSensitization of $\mathrm{TiO}_{2}$. Inorg. Chem. 2012, 51, 3981-3988.

(22) Leigh, V.; Ghattas, W.; Lalrempuia, R.; Muller-Bunz, H.; Pryce, M. T.; Albrecht, M. Synthesis, Photo-, and Electrochemistry of Ruthenium Bis(bipyridine) Complexes Comprising a N-heterocyclic carbene Ligand. Inorg. Chem. 2013, 52, 5395-5402.

(23) (a) Ashford, D. L.; Glasson, C. R.; Norris, M. R.; Concepcion, J. J.; Keinan, S.; Brennaman, M. K.; Templeton, J. L.; Meyer, T. J. Controlling Ground and Excited State Properties Through Ligand Changes in Ruthenium Polypyridyl complexes. Inorg. Chem. 2014, 53, 5637-5646. (b) Suzuki, K.; Kobayashi, A.; Kaneko, S.; Takehira, K.; Yoshihara, T.; Ishida, H.; Shiina, Y.; Oishi, S.; Tobita, S. Reevaluation of Absolute Luminescence Quantum Yields of Standard Solutions Using a Spectrometer with an Integrating Sphere and a Back-Thinned CCD Detector. Phys. Chem. Chem. Phys. 2009, 11, 9850-9860.

(24) (a) Rapp, T. L.; Phillips, S. R.; Dmochowski, I. J. Kinetics and Photochemistry of Ruthenium Bisbipyridine Diacetonitrile Complexes: An Interdisciplinary Inorganic and Physical Chemistry Laboratory Exercise. J. Chem. Educ. 2016, 93, 2101-2105. (b) Yoshikawa, N.; Kimura, H.; Yamabe, S.; Kanehisa, N.; Inoue, T.; Takashima, H. Emission Property and DFT Calculation for the ${ }^{3}$ MLCT Luminescence of $\mathrm{Ru}(\text { bpy })_{2}(\mathrm{~L})^{2+}$ Complex. J. Mol. Struct. 2016, 1117, 49-56

(25) Henderson, L. J., Jr; Fronczek, F. R.; Cherry, W. R. Selective Perturbation of Ligand Field Excited States in Polypyridine Ruthenium(II) Complexes. J. Am. Chem. Soc. 1984, 106, 5876-5879.

(26) Yoshimura, A.; Hoffman, M. Z.; Sun, H. An Evaluation of the Excited State Absorption Spectrum of $\mathrm{Ru}(\text { bpy })_{3}{ }^{2+}$ in Aqueous and Acetonitrile Solutions. J. Photochem. Photobiol., A 1993, 70, 29-33.

(27) (a) Thompson, A. M. W. C.; Jeffery, J. C.; Liard, D. J.; Ward, M. D. Mono-and Di-Nuclear Ruthenium (II) Complexes of the Ambidentate Ligand 3,3'-Dihydroxy-2,2'-bipyridine: Spectroscopic, Electrochemical and Mixed-Valence Properties. J. Chem. Soc., Dalton Trans. 1996, 879-884. (b) Ghosh, P.; Ray, R.; Das, A.; Lahiri, G. K. Revelation of Varying Coordination Modes and Noninnocence of Deprotonated 2,2'-Bipyridine-3,3'-diol in $\left\{\mathrm{Os}(\mathrm{bpy})_{2}\right\}$ Frameworks. Inorg. Chem. 2014, 53, 10695-10707.

(28) Kunkely, H.; Vogler, A. Optical Properties of (3,3'-Dihydroxy2,2'-bipyridine)Tricarbonyl-Rhenium (I) Chloride. Absorption and Emission Spectra. Inorg. Chim. Acta 2003, 343, 357-360.

(29) Connelly, N. G.; Geiger, W. E. Chemical Redox Agents for Organometallic Chemistry. Chem. Rev. 1996, 96, 877-910.

(30) Kaljurand, I.; Kütt, A.; Sooväli, L.; Rodima, T.; Mäemets, V.; Leito, I.; Koppel, I. A. Extension of the Self-Consistent Spectrophotometric Basicity Scale in Acetonitrile to a Full Span of $28 \mathrm{p} K_{\mathrm{a}}$ Units: Unification of Different Basicity Scales. J. Org. Chem. 2005, 70, 10191028.

(31) Henstridge, M. C.; Laborda, E.; Rees, N. V.; Compton, R. G. Marcus-Hush-Chidsey Theory of Electron Transfer Applied to Voltammetry: A Review. Electrochim. Acta 2012, 84, 12-20.

(32) (a) Evans, D. H.; Hu, K. Inverted Potentials in Two-Electron Processes in Organic Electrochemistry. J. Chem. Soc., Faraday Trans. 1996, 92, 3983-3990. (b) Hammerich, O. In Organic Electro- chemistry, 5th ed.; Revised and Expanded; Speiser, B., Eds.; CRC Press: LLC, 2015.

(33) (a) Lachmanová, S.; Dupeyre, G.; Tarábek, J.; Ochsenbein, P.; Perruchot, C.; Ciofini, I.; Hromadová, M.; Pospísil, L.; Lainé, P. P. Kinetics of Multielectron Transfers and Redox-Induced Structural Changes in N-Aryl-Expanded Pyridiniums: Establishing Their Unusual, Versatile Electrophoric Activity. J. Am. Chem. Soc. 2015, 137, 11349-11364. (b) Fortage, J.; Peltier, C.; Perruchot, C.; Takemoto, Y.; Teki, Y.; Bedioui, F.; Marvaud, V.; Dupeyre, G.; Pospísil, L.; Adamo, C.; Hromadová, M.; Ciofini, I.; Lainé, P. P. Single-Step versus Stepwise Two-Electron Reduction of Polyarylpyridiniums: Insights from the Steric Switching of Redox Potential Compression. J. Am. Chem. Soc. 2012, 134, 2691-2705.

(34) Schulzke, C. Temperature Dependent ElectrochemistryAVersatile Tool for Investigations of Biology Related Topics. Dalton Trans. 2009, 6683-6691.

(35) Bard, A. J.; Faulkner, L. R. Electrochemical methods: Fundamentals and Applications; Wiley: New York, 2001; Vol. 2.

(36) Tsierkezos, N. G. Cyclic Voltammetric Studies of Ferrocene in Nonaqueous Solvents in the Temperature Range from 248.15 to 298.15 K. J. Solution Chem. 2007, 36, 289-302.

(37) Bard, A. J.; Faulkner, L. R. Electrochemical methods: Fundamentals and Applications; Wiley: New York, 2001; p 87.

(38) (a) Costentin, C.; Robert, M.; Savéant, J.-M. Reorganization Energies and Pre-exponential Factors in the One-Electron Electrochemical and Homogeneous Oxidation of Phenols Coupled with an Intramolecular Amine-Driven Proton Transfer. Phys. Chem. Chem. Phys. 2010, 12, 13061-13069. (b) He, Z. D.; Chen, Y. X.; Santos, E.; Schmickler, W. The Pre-exponential Factor in Electrochemistry. Angew. Chem., Int. Ed. 2018, 57, 7948-7956. 